$$
\begin{gathered}
\angle A-S U B-97-10 \\
\text { RECEVIVD } \\
\text { JUL } 251997 \\
\text { OSTI }
\end{gathered}
$$

\title{
Opportunities for Russian Nuclear Weapons Institute Developing Computer-Aided Design Programs for Pharmaceutical Drug Discovery
}

\author{
Final Report \\ September 23, 1996
}

\author{
Kendall Strategies \\ Cambridge, MA
}

\begin{abstract}
DISCLAIMER
This report was prepared as an account of work sponsored by an agency of the United States Government. Neither the United States Government nor any agency thereof, nor any of their employees, makes any warranty, express or implied, or assumes any legal liability or responsibility for the accuracy, completeness, or usefulness of any information, apparatus, product, or process disclosed, or represents that its use would not infringe privately owned rights. Reference herein to any specific commercial product, process, or service by trade name, trademark, manufacturer, or otherwise does not necessarily constitute or imply its endorsement, recommendation, or favoring by the United States Government or any agency thereof. The views and opinions of authors expressed herein do not necessarily state or reflect those of the United States Government or any agency thereof.
\end{abstract}




\section{DISCLAMMER}

Portions of this document may be illegible in electronic image produets. Images are produced from the best available original document. 


\section{Table of Contents}

Page No.

I. Abstract

II. A Growing Demand to Improve Drug Discovery Efficiency

6

III. A Small, \$185 Million Business That is Highly Dependent on Academic Research for New Programs

IV. A Shifting Focus Away From Structure-Based Design

V. Significant Opportunities Exist for Improved CADD Programs 21

VI. Four Business Models for Building a CADD Company

28

VII. A Successful CADD Company Depends on Five Key Factors

30

VIII. Conclusions

IX. Appendices
A Methodology
B Major Competitors
C Interview Notes 


\section{Opportunities for Russian Nuclear Weapons Institute Developing Computer-Aided Design Programs for Pharmaceutical Drug Discovery}

\section{Abstract}

The goal of this study is to determine whether physicists at the Russian Nuclear Weapons Institute can profitably service the need for computer aided drug design (CADD) programs. The Russian physicists' primary competitive advantage is their ability to write particularly efficient code able to work with limited computing power; a history of working with very large, complex modeling systems; an extensive knowledge of physics and mathematics, and price competitiveness. Their primary competitive disadvantage is their lack of biology, and cultural and geographic issues.

The first phase of the study focused on defining the competitive landscape, primarily through interviews with and literature searches on the key providers of CADD software. The second phase focused on users of CADD technology to determine deficiencies in the current product offerings, to understand what product they most desired, and to define the potential demand for such a product. The respondents divided as follows:

$\begin{array}{lll}\text { - } & \text { Commercial Software Companies } & 3 \\ \text { - } \quad \text { Piotechnology Companies } & 9 \\ \text { - Academaceutical Companies } & 6 \\ & & 9 \\ & & \text { Total }\end{array}$

The Value of $C A D D$

Pharmaceutical research is undergoing fundamental changes in the ways in which it identifies new drug candidates. As the understanding of molecular biology, medicinal chemistry, human physiology, medicine, etc., has mushroomed, the potential to produce truly effective new medicines has increased accordingly. Continuing pharmaceutical breakthroughs have demonstrated that advanced drugs are truly able to alter the course of disease.

The result has been ever increasing pressure on drug developers to derive new compounds that are safe and effective, driving a parallel exponential growth in the demand for systems that increase the efficiency and output of the drug discovery process. All of this has lead to the development of a large cottage industry of entrepreneurial companies, including biotechnology, devoted to uncovering novel drug candidates.

The primary areas for efficiency increases in the pharmaceutical development process are:

- increasing the number of lead candidates;

- developing refined screens to more accurately select potential drug leads; 
- increasing the likelihood that a lead candidate can turn into a successful drug by altering a lead's chemical structure; and

- early elimination of those candidates that are unlikely to work.

\section{The Dynamic Value of Lead Generation}

The social and economic value of new drugs is so great that pharmaceutical companies spend hundreds of millions of dollars in capital resources and decades of time for each compound marketed. The rewards are commensurate with the risk: blockbuster products produce revenues beyond a billion dollars a year. But, even the largest pharmaceutical company is able to produce a major product only every four of five years. Therefore, even a relatively small reduction in time or expense is worth tens of millions of dollars. Such gains spread over a series of products are worth hundreds of millions of dollars.

Classical drug design is an iterative approach that uses the properties of known compounds as a basis for generating new leads. It is often described as a "lock-and-key" system. Drug companies maintain extensive libraries of locks without keys and keys without locks. Traditionally, each time researchers find a new key, they try it on all the locks; every time a new lock is discovered, it is mated with all the keys. And, to make it more interesting, both the locks and the keys are invisible and must be reconstructed each time they are tested.

Therefore, a CADD program which could provide insight into the structure and function of a disease target (the locks), or the drug candidate (the key), can accelerate the drug discovery process by avoiding the need for making costly physical iterations.

CADD is theoretically capable of adding value by directing researchers towards those chemicals likely to be successful, and eliminating compounds with a low likelihood of success. Proof, however, has only been recent: CADD was instrumental in the design of protease inhibitors, one of the most promising new drug treatments for HIV infections, and is given extensive credit for the development of Aggrastat, an antithrombolytic.

\section{Combinatorial Chemistry and Automated Lead-Generation}

The primary competitors to CADD are automated systems that greatly increase the rate of production of new compounds in a logical framework, or that increase the rate of matching locks with keys. Recently, advances in automation have far outstripped advances in computational programs used to model the locks and keys. These combinatorial systems and high-speed gene sequencing systems create demand for information management computer programs due to the vast amount of data they create.

\section{The Current CADD Industry Is Small}

Though intellectually attractive, CADD has produced few successful drugs, and the number of companies devoted to the marketing of CADD software are relatively small. Considering the potential for enhancing the drug discovery process, the current size of the CADD sector, estimated to be $\$ 185$ million in annual sales, is puny. 
Most of the current CADD companies rely on academic labs for new product ideas. The commercial ventures then package, market and service the software. The commercial organizations produce little new code. Companies have shied away from risking their own money in new product research, so that available CADD programs are old and unimproved. One respondent reported that renewal contracts from existing products generated $86 \%$ of software license sales; only $14 \%$ was from new product sales. Another reported that renewals generate $63 \%$ of total revenues. An industry norm appeared to be about $17 \%$ of net sales spent on R\&D, with much of it concentrated on developing user friendly interfaces, debugging software and interfacing one CADD software program with another. One respondent reported that employees spend only 20 percent of $\mathrm{R} \& \mathrm{D}$ time on developing novel algorithms. The common response to increasing revenues has been to focus on developing easier, not better, programs, increasing the number of users and therefore the number of licenses at each customer site.

In addition to the age of the product, potential customers reported that available products were of poor and uneven quality. A key issue is lack of accuracy in programs; early computer simulations were particularly inaccurate due to the complexity of chemical and biological phenomena and a lack of understanding of physics.

An obvious inference is that the market's concentrated nature is due to saturated demand for existing, low-quality modeling software.

\section{Conclusions}

A large potential market exists for new CADD software. The area of greatest competitive advantage is against the academic sources of code and not the commercial ventures focused on service, incremental improvements in programs, and user friendly interfaces. Physicists working in isolation from the marketplace must focus by necessity on large projects and have limited customer contact.

The more complex CADD programs can take up to 3-5 years to develop and generate revenues of up to $\$ 10-15$ million. If a commercial venture could establish true value-added pricing structures, these revenue numbers would increase dramatically.

A successful CADD company will depend on five key factors:

- Securing a strong scientific advisory board from which a knowledge of biology and the marketplace can be derived;

- Identifying large problems with payoffs sufficient to offset the investment risk;

- Validating the Russian's capabilities early to attract investors;

- Building a strong U.S. administrative base to find customers and financial backers;

- Identifying interim project milestones that create value short of $100 \%$ completion. 


\section{A Growing Demand to Improve Drug Discovery Efficiency}

Pharmaceutical research is undergoing fundamental changes in the ways in which it identifies new drug candidates. Therapeutic targets are being characterized at an ever increasing rate, providing scientists with a better understanding than before of how to guide new drug design. In addition, high-speed methods for generating and screening drug leads have emerged, which dramatically reduce the costs of generating drug candidates compared to labor-intensive manual chemistry techniques.

Despite these technical advances, drug discovery is becoming less efficient each year. According to the Pharmaceutical Research and Manufacturers of America (PhRMA), pharmaceutical industry R\&D spending has almost tripled the past ten years from $\$ 4$ billion to over $\$ 15$ billion. During this same time frame, the number of new chemical entities (NCEs) approved has remained flat at 20-30 NCEs a year (Figure 1).

Figure 1

Number of NCE's vs. R\&D Expense

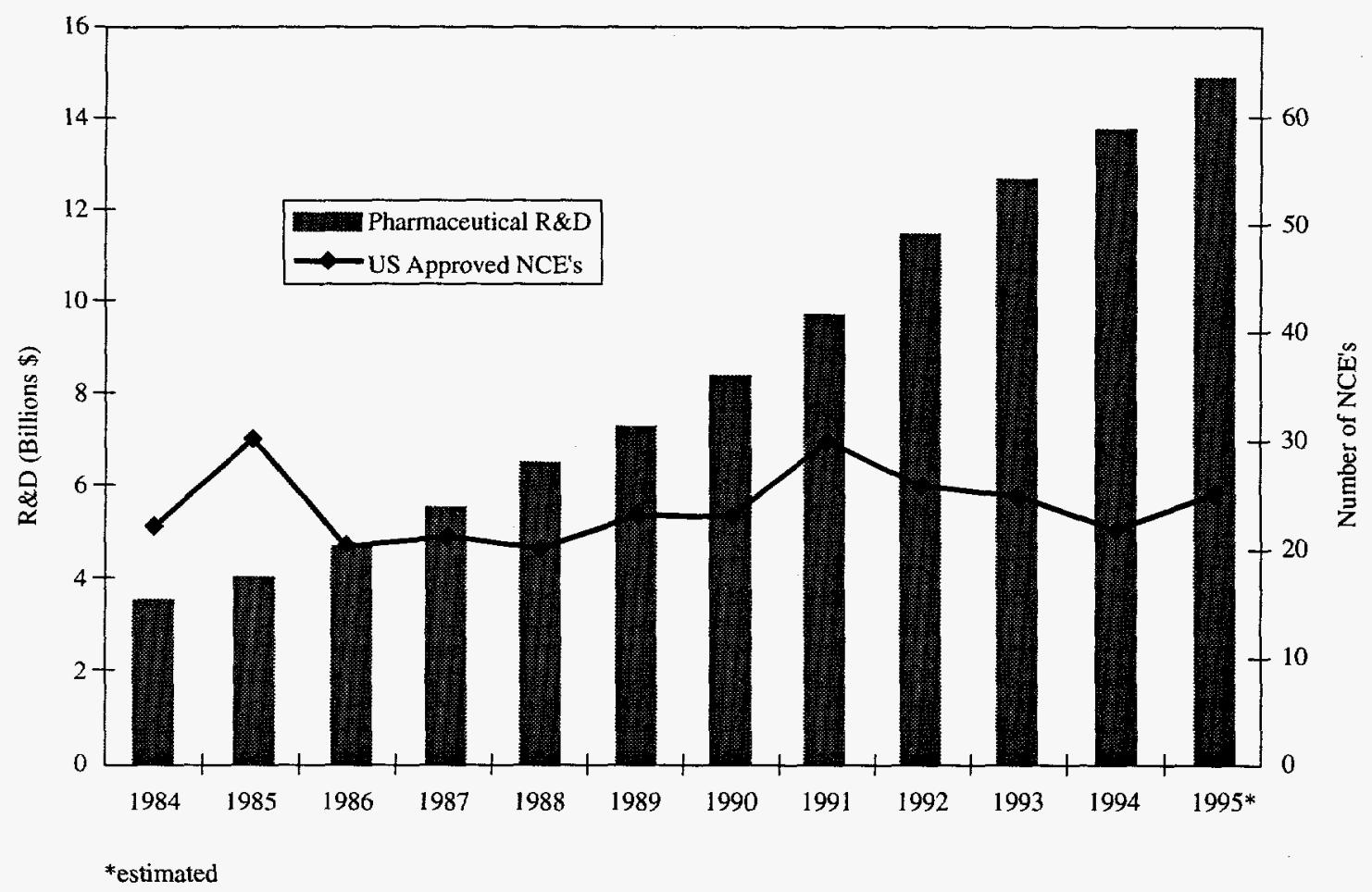

Source: PhRMA (R\&D) and FDA (NCE's)

These trends have lead to an urgent, ever-growing need for improvements in current computer-aided drug design (CADD) software. Scientists need CADD programs which can provide insights into the structural and functional activity of a disease target, giving them the biological map they need to develop a drug without making costly physical iterations. Efficiently analyzing and managing the soaring amount of information being 
generated from high speed synthetic techniques requires additional CADD software. Together, more efficient software programs could dramatically reduce drug development costs by quickly simulating on a computer what might takes days to perform experimentally. Not only could experiments be easier and less expensive, but more experiments could be performed in the same amount of time, dramatically improving research productivity.

The history of CADD dates back over 30 years. For example, leading quantum mechanics programs like Gaussian, and force field calculation programs such as Charmm, Amber, Discover, are based on research published in the 1960's. Originally, their use was confined to academia. In the late 1970's and early 1980's, however, they began to find use in industry with the founding of commercial CADD software companies. Included among the early commercial pioneers were MDL Information Systems and Tripos, Inc., founded in 1978 and 1979 respectively, and BioSym and Polygen, both founded in the mid-80's and now part of Molecular Simulations Inc. (MSI). Other companies that played leading roles in developing the CADD industry include Chemical Design (1983) and Oxford Molecular Group (1989).

Early CADD programs proved extremely limited. Using graphical programs, scientists could precisely visualize a molecule's three dimensional structure. Few programs, however, could short-cut traditional wet chemistry methodologies. The programs were difficult to use and time-consuming to run, and pharmaceutical companies lacked the necessary specialists to operate them. Most importantly, early computer coded simulations were inaccurate due to the complexity of chemical and biological phenomena.

Though significant limitations still exist in today's products, biotechnology and pharmaceutical industries, as well as chemical, agricultural and plastics researchers, now widely use computer-aided design in their work. Most pharmaceutical and biotechnology companies now have dedicated departments of computational specialists who work closely with medicinal chemists and molecular biologists in new drug identification and development. Not only has CADD become an important adjunct to the search for new drugs, but examples exist where it has played a lead role in identifying a new drug. In particular, CADD was instrumental in the design of protease inhibitors, one of the most promising new drug treatments for HIV infections. CADD is also given extensive credit for the development of Aggrastat, a novel antithrombolytic developed by Merck now in clinical trials.

Scientists expect CADD's role to become even more prominent in the future. Drug development has undergone a dramatic transformation the past few years with the introduction of very efficient discovery processes, such as high throughput screening, combinatorial chemistry, automated gene sequencing and rational drug design. These technologies have produced a multi-fold increase in the pace of lead generation, identification and optimization, dramatically increasing research productivity. Using traditional approaches, generation of potential leads was limited to 100-200 analogs per chemist at a cost of $\$ 7,500$ per compound. Once identified, it would take about two years to optimize a lead into a potential drug candidate. Today, libraries consisting of 100,000 compounds or more can be rapidly generated using high throughput screening and combinatorial chemistry. Scientists can then evaluate them against a growing array of targets that have been identified and characterized using automated gene sequencing and 
rational drug design. The promise of these approaches is reflected in the money that has been invested in these technologies as measured by the value of the deals consummated in 1995. (Figure 2)

Figure 2

\section{Acquisitions, Financings, Strategic Alliances 1995 \$ Millions}

\begin{tabular}{|c|c|c|}
\hline & Total Value (\$MM) & Major Examples \\
\hline Combinatorial Chemistry & 1,212 & $\begin{array}{l}\text { ArQule, Chiron, Gilead, } \\
\text { Pharmacopeia }\end{array}$ \\
\hline High Throughput Screening & 1,403 & $\begin{array}{l}\text { Affymax (Glaxo), Millennium, } \\
\text { Human Genome Sciences, Incyte, } \\
\text { Sequana }\end{array}$ \\
\hline Rational Drug Design & 296 & Agouron, Vertex \\
\hline
\end{tabular}

* Applied Biosystems owns $80 \%$ of automated gene sequencer market; Perkin-Elmer bought Applied Biosystems for $\$ 330$ million in 1992

These technologies are expanding the CADD industry beyond its role of experimental simulation and graphical representation, to the expression, management and analysis of populations of information. These growing demands are most clearly demonstrated in two popular approaches to drug discovery: classical drug design and structure-based design. Classical drug design is an iterative approach that uses the properties of known compounds as a basis for generating new leads. As one interviewee described it, the scientist "designs a key not knowing what the lock [target] is but knowing what types of keys will fit into the lock." Combinatorial chemistry is a high-speed variation of classical drug design whereby thousands of drug combinations are rapidly generated. High throughput screening is then used to identify "hits". These two advances in classical drug design create enormous amounts of data, opening opportunities for managing large amounts of information.

Structure-based design, also called rational-based drug design, works in reverse. The scientist first characterizes the target and then attempts to design molecules that fit it. In effect, the scientist designs the key knowing what the lock is. Optimizing a drug's design using this approach requires sophisticated computational methodologies for simulating molecular interactions. Accuracy has always been the most important factor in these programs, but with the growing popularity of combinatorial chemistry, computational speed has now become a critical factor. Combinatorial chemistry and high throughput screening have introduced an element of "sloppiness" into the drug search process, making it easier and potentially faster to generate a lead by creating a library of chemical analogues than through the meticulous process of building a lead from an understanding of its target. Molecular modelers involved in developing this simulation software now face the daunting task of developing programs that are not only more accurate but also faster. 


\section{A Small, $\$ 185$ Mil. Business That is Highly Dependent on Academic Research for New Programs}

Despite the clear need for CADD programs in the drug discovery process, industry sales amounted to only $\$ 185$ million in 1995 (Figure 3). Most of the large pharmaceutical companies carry a variety of molecular modeling and information management programs, the two major software categories. These include commercial packages, programs developed in academia and programs developed in-house. The widespread acceptance of these programs belies their modest impact on drug discovery efficiency. Companies have shied away from risking their own money in new product research. Instead, they have held onto their traditional role as developers and marketers of software designed by academics whose R\&D budgets are limited by the size of government grants. The result is software programs with few novel features and an industry that languishes far below its potential.

This lack of innovation is most clearly evident in the older, modeling segment of the business. Total CADD industry revenues grew about 12 percent last year, increasing from $\$ 165$ million to $\$ 185$ million. ${ }^{1}$ Practically all of this growth is due to increases in the information management sector. MDL Information Systems, the leading company in the data management business, accounted for approximately half of the $\$ 20$ million revenue increase. Companies in the molecular modeling segment had only a modest sales increase. Earnings suffered from write-offs due to product failures or to costs associated from buying out competitors, a phenomenon that has characterized the modeling business the past few years. Oxford Molecular, the one exception, reported a significant increase in sales but from a low base of only around $\$ 4.3$ million.

Revenues in the industry come primarily from the sale of software licenses, software updates, maintenance contracts and sales of hardware manufactured by Silicon Graphics and other companies and distributed by software providers as part of the initial installation. Updates, renewals and maintenance contracts on existing products generate a significant amount of software licensing revenue. For example, existing contracts generated $86 \%$ of Tripos' 1995 software license sales; only $14 \%$ was from new product sales. At MDL, renewals generated $63 \%$ of total database revenues. The revenue generated from existing products provides each company with a considerable annuity.

\section{Competitive Environment}

The CADD industry is a highly concentrated market. An estimated 17 companies compete in the business. The top four companies account for 75 percent of the industry, leaving 25 percent of the business to be split among the remaining thirteen. Except for Chemical Design, all of the remaining companies are private. A majority sells one or two specific software packages and have revenues of less than $\$ 1$ million. Included in this group are several firms that were founded by university professors and that are operated as an extension of their academic activities.

\footnotetext{
${ }^{1}$ MMCC Publishing \& Consulting, "Computational Chemistry and Molecular Modeling," Fifth Annual Industry Report, April 1996.
} 
Figure 3

\section{CADD Software Market Segmentation}

\begin{tabular}{|c|c|c|c|}
\hline Category & Description & Sales (\$MM) & Market Share \\
\hline $\begin{array}{l}\text { Molecular Modeling } \\
\text { - Graphical, Similarity/Diversity } \\
\text { Programs } \\
\text { - Computation Programs }\end{array}$ & $\begin{array}{l}\text { - Graphical programs for viewing molecules. Programs } \\
\text { for characterizing the similar/dissimilar } \\
\text { characteristics of an unknown molecule with a } \\
\text { known molecule } \\
\text { - Programs for modeling intermolecular forces and } \\
\text { predicting binding energies. }\end{array}$ & $\$ 45.0$ & $\begin{array}{l}24.3 \% \\
27.0\end{array}$ \\
\hline $\begin{array}{l}\text { Information Management } \\
\text { - Chemical Information Software } \\
\text { - Chemical Information Software } \\
\text { - Bioinformatics }\end{array}$ & $\begin{array}{l}\text { - Programs for data searching, molecular } \\
\text { structure/analysis. Incorporates similarity algorithms } \\
\text { - Chemical abstract/information libraries, including } \\
\text { combinatorial chemistry libraries } \\
\text { - Protein sequence databases and database software } \\
\text { Total }\end{array}$ & $\begin{array}{r}63.0 \\
22.0 \\
5.0 \\
\$ 185.0\end{array}$ & $\begin{array}{r}34.0 \\
12.0 \\
2.7 \\
100.0 \%\end{array}$ \\
\hline
\end{tabular}

Source: MMCC Publishing \& Consulting, Kendall Strategies 
The market's concentrated nature is due to saturated demand for existing modeling software. Pharmaceutical companies have found little reason to expand their modeling activities given the limitations with current programs. CADD companies have responded by acquiring smaller companies in order to leverage their marketing costs across a broader product portfolio. The effect has been significant industry consolidation the past several years. For example, Oxford Molecular acquired BioStructure in 1993, its leading European competitor, Intelligenics in 1994, and CAChe Scientific in 1995. This year it has purchased three companies, including Health Designs Inc., the leading provider of toxicology software. Similarly, Molecular Simulation Inc. (MSI) purchased Cambridge Molecular Design and Polygen in 1991, BioCAD in 1994 and BioSym in 1995. BioSym had been owned by Corning. As a result of its investment in BioSym, Corning owns a 55 percent interest in MSI.

Figure 4

\section{Competitive Market Shares}

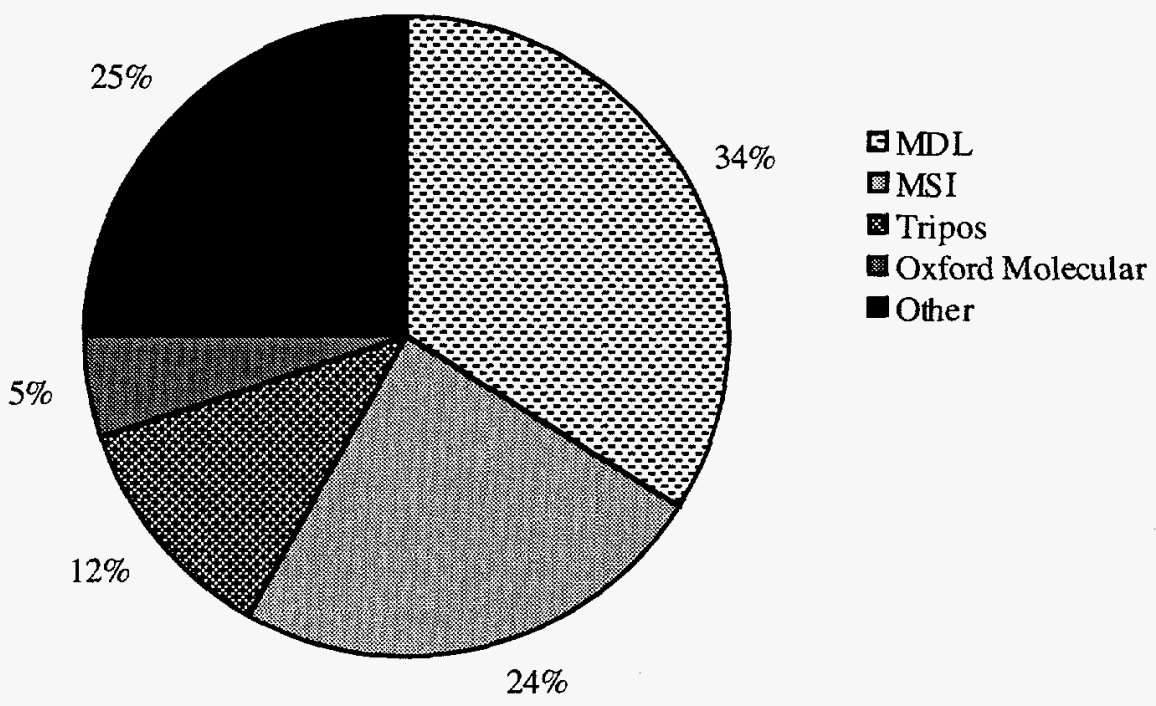

Products

Most of the companies in the business offer products in at least two of the five product segments (Figure 5). Within each segment, a company may sell a number of programs, each one addressing a specific niche application (e.g., quantum mechanics, ligand docking, free energy perturbation). Although designed to be application specific, each company will also build into its suite of programs a great deal of overlapping functionality. This full-featured strategy adds to the value of a single program sale, but for the company buying a suite of programs from one supplier, the strategy diminishes the incremental value of each program. Comparing competing programs, the consensus among interviewees was that there are only minor differences. In cases, as a result of the consolidations that have occurred in the industry, there are often overlapping programs within a company. A product listing, including descriptions, of software sold by the larger companies is found in Appendix B. 
Figure 5

CADD Companies By Business Segment

\begin{tabular}{|c|c|c|c|c|c|c|c|}
\hline Company & $\begin{array}{l}\text { Molecular } \\
\text { Computation }\end{array}$ & $\begin{array}{l}\text { Graphics, } \\
\text { Modeling }\end{array}$ & $\begin{array}{l}\text { Chem Info } \\
\text { (Software) }\end{array}$ & $\begin{array}{l}\text { Chem Info } \\
\text { (Databases) }\end{array}$ & Bioinformatics & $\begin{array}{c}\text { Date } \\
\text { Founded }\end{array}$ & Summary \\
\hline Beilstein Info. Systems & & & & - & & 1983 & $\begin{array}{l}\text { - Owned jointly by Information } \\
\text { Handling Services (Englewood, } \\
\text { CO) and Beilstein Institute of } \\
\text { Frankfort } \\
\text { - Estimated } 30-35 \text { employees } \\
\text { worldwide } \\
\text { - Core product is Cross-Fire, } \\
\text { electronic version of Beilstein file, } \\
\text { one of the world's primary source } \\
\text { for chemical data }\end{array}$ \\
\hline CambridgeSoft Corp. & & & - & & & 1986 & $\begin{array}{l}\text { - Approx. } 25 \text { employees; private } \\
\text { - Revenues estimated at } \$ 5 \text { million } \\
\text { - Core ChemOffice product consists } \\
\text { of Cs ChemDraw, Cs Chem } 3 \mathrm{D}, \mathrm{Cs} \\
\text { ChemFinder }\end{array}$ \\
\hline Chemical Design & - & $\bullet$ & - & & & 1983 & $\begin{array}{l}\text { - Core product is Chem-X: an } \\
\text { integrated package that includes } \\
\text { model-building, computation, } \\
\text { graphics and chemo information } \\
\text { applications } \\
\text { - Company has good track record of } \\
\text { customer support/development of } \\
\text { custom software } \\
\text { - Initiated IPO in August } 1996\end{array}$ \\
\hline
\end{tabular}




\section{CADD Companies By Business Segment (cont.)}

\begin{tabular}{|c|c|c|c|c|c|c|c|}
\hline Company & $\begin{array}{c}\text { Molecular } \\
\text { Computation }\end{array}$ & $\begin{array}{l}\text { Graphics, } \\
\text { Modeling }\end{array}$ & $\begin{array}{l}\text { Chem Info } \\
\text { (Software) }\end{array}$ & $\begin{array}{l}\text { Chem Info } \\
\text { (Databases) }\end{array}$ & Bioinformatics & $\begin{array}{c}\text { Date } \\
\text { Founded }\end{array}$ & Summary \\
\hline $\begin{array}{l}\text { Daylight Chemical } \\
\text { Information Systems }\end{array}$ & & & - & - & & 1986 & $\begin{array}{l}\text { - Revenues doubled in } 1995 \\
\text { - Caters to individual customer } \\
\text { versus entire IT group } \\
\text { - Known to be creative/original in } \\
\text { sales methods (i.e., no fancy } \\
\text { presentations) }\end{array}$ \\
\hline Gaussian, Inc. & - & & & & & 1987 & $\begin{array}{l}\text { - Approximately } 10 \text { employees } \\
\text { - Gaussian program considered gold } \\
\text { standard of ab initio molecular } \\
\text { competition } \\
\text { - Program has enormous flexibility } \\
\text { and functionality }\end{array}$ \\
\hline Hypercube, Inc. & - & - & & & & 1983 & $\begin{array}{l}\text { - Approximately } 12 \text { employees } \\
\text { - Software sold through } \\
\text { distributor/network } \\
\text { - HyperChem product the leader } \\
\text { among PC programs with } \\
\text { semiempirical and ab initio } \\
\text { capabilities }\end{array}$ \\
\hline Interactive Simulations & & - & & & & 1994 & $\begin{array}{l}\text { - Raised } \$ 2 \text { million in venture } \\
\text { financing and } \$ 1 \text { million in SBIR } \\
\text { grants in past year } \\
\text { - First product is SCULPT - } \\
\text { modeling program about force } \\
\text { structure } \\
\text { - Considered a company to watch }\end{array}$ \\
\hline
\end{tabular}


CADD Companies By Business Segment (cont.)

\begin{tabular}{|c|c|c|c|c|c|c|c|}
\hline Company & $\begin{array}{l}\text { Molecular } \\
\text { Computation }\end{array}$ & $\begin{array}{l}\text { Graphics, } \\
\text { Modeling } \\
\end{array}$ & $\begin{array}{l}\text { Chem Info } \\
\text { (Software) }\end{array}$ & $\begin{array}{l}\text { Chem Info } \\
\text { (Databases) }\end{array}$ & Bioinformatics & $\begin{array}{c}\text { Date } \\
\text { Founded }\end{array}$ & Summary \\
\hline $\begin{array}{l}\text { MDL Information } \\
\text { Systems }\end{array}$ & & & - & $\bullet$ & & 1978 & $\begin{array}{l}\text { - } \$ 61.5 \mathrm{M} \text { in revenues in } 1995 \\
\text { - Entered into several partnerships } \\
\text { with combinatorial chemistry and } \\
\text { HTS products } \\
\text { - In fourth quarter } 1995 \text { had } 13 \text { ISIS } \\
\text { orders of } \$ 100,000+ \\
\text { - Has no significant competition for } \\
\text { large-scale installations }\end{array}$ \\
\hline $\begin{array}{l}\text { Molecular Applications } \\
\text { Group }\end{array}$ & & $\bullet$ & & & - & 1990 & $\begin{array}{l}\text { - Raised } \$ 3.5 \text { million in late } 1995 \\
\text { through second round financing; } \\
\text { backers include Morgenthaler } \\
\text { Ventures } \\
\text { - Approximately } 25 \text { employees } \\
\text { - LOOK products integrates } \\
\text { sequence/structure analysis, } \\
\text { modeling tools and info from } \\
\text { Web; product got "rave reviews" } \\
\text { - One of the first companies to take } \\
\text { advantage of World Wide Web } \\
\text { - Senior management has strong } \\
\text { science background }\end{array}$ \\
\hline $\begin{array}{l}\text { Molecular Simulations } \\
\text { Inc. }\end{array}$ & - & - & - & & & 1984 & $\begin{array}{l}\text { - Revenues estimated at } \$ 45-50 \\
\text { mil. } \\
\text { - Business units include Life } \\
\text { Sciences and Materials Sciences } \\
\text { - Recently started combinatorial } \\
\text { chemistry consortium }\end{array}$ \\
\hline
\end{tabular}


CADD Companies By Business Segment (cont.)

\begin{tabular}{|c|c|c|c|c|c|c|c|}
\hline Company & $\begin{array}{l}\text { Molecular } \\
\text { Computation }\end{array}$ & $\begin{array}{l}\text { Graphics, } \\
\text { Modeling }\end{array}$ & $\begin{array}{l}\text { Chem Info } \\
\text { (Software) }\end{array}$ & $\begin{array}{l}\text { Chem Info } \\
\text { (Databases) }\end{array}$ & Bioinformatics & $\begin{array}{c}\text { Date } \\
\text { Founded }\end{array}$ & Summary \\
\hline Oxford Molecular Group & • & $\bullet$ & - & & $\bullet$ & 1989 & $\begin{array}{l}\text { - Approx. } \$ 10 \text { mil. in } 1995 \text { revenues } \\
\text { - Generated } \$ 26 \text { million cash in } \\
1995 \text { offering } \\
\text { - Recent agreement with } \\
\text { Yamanouchi worth } \$ 10 \text { million+ } \\
\text { over three years }\end{array}$ \\
\hline Schrödinger, Inc. & $\bullet$ & & & & & 1990 & $\begin{array}{l}\text { - Offers core suite of quantum } \\
\text { chemistry programs }\end{array}$ \\
\hline SciVision & & - & & - & & 1994 & $\begin{array}{l}\text { - Approx. } 25 \text { employees; } 21 \text { located } \\
\text { in Russia } \\
\text { - Products mostly in structure- } \\
\text { property prediction field } \\
\text { - Distribution channel with Tripos } \\
\text { - Core product is SciVision structure } \\
\text { and property relational databases }\end{array}$ \\
\hline Semichem & - & & & & & 1992 & $\begin{array}{l}\text { - Mostly semi-empirical modeling } \\
\text { programs }\end{array}$ \\
\hline Serena Software & - & - & & & & 1985 & $\begin{array}{l}\text { - Three employees } \\
\text { - PCModel product - a molecular } \\
\text { mechanics package using MMX } \\
\text { force field }\end{array}$ \\
\hline
\end{tabular}




\section{CADD Companies By Business Segment (cont.)}

\begin{tabular}{|c|c|c|c|c|c|c|c|}
\hline Company & $\begin{array}{c}\text { Molecular } \\
\text { Computation }\end{array}$ & $\begin{array}{l}\text { Graphics, } \\
\text { Modeling }\end{array}$ & $\begin{array}{l}\text { Chem Info } \\
\text { (Software) }\end{array}$ & $\begin{array}{l}\text { Chem Info } \\
\text { (Databases) }\end{array}$ & Bioinformatics & $\begin{array}{c}\text { Date } \\
\text { Founded }\end{array}$ & Summary \\
\hline Tripos & • & - & - & & & 1979 & $\begin{array}{l}\text { - } \$ 21.1 \mathrm{M} \text { in } 1995 \text { revenues } \\
\text { Organized into two major groups: } \\
\text { Software Product Management and } \\
\text { Accelerated Discovery Services } \\
\text { - Entered two key alliances in 1996: } \\
\text { Panlabs and MDL Information } \\
\text { Systems } \\
\end{array}$ \\
\hline Wavefunction & - & - & & & & 1991 & $\begin{array}{l}\text { - Approximately } 15 \text { employees } \\
\text { - Core product is SPARTAN } 4.1 \text {, } \\
\text { program for density functional, } \\
\text { semiempirical and force field } \\
\text { calculations through a graphical } \\
\text { user interface }\end{array}$ \\
\hline
\end{tabular}

Source: MMCC Publishing 
Software programs can cost anywhere from $\$ 1000$ to more than $\$ 100,000$ for a large commercial program, with yearly maintenance/product support fees typically 15 percent of the sale price, an option subscribed to in 90 percent of cases $^{2}$. Programs from the top commercial companies are sold on a per-seat or per-site basis. The top software programs are compatible with both the PC and Macintosh systems. Generally, programs are structured to run on networked desktop computers, with the calculations performed remotely on high performance servers.

\section{Purchasing Decisions}

The primary users of computer-aided design software are computational specialists who have backgrounds in computational chemistry, structural biology, medicinal chemistry, synthetic chemistry or molecular biology. With the growth of combinatorial chemistry, pharmaceutical companies are also hiring "informaticists" with skills in managing and developing their combinatorial libraries. Most of these specialists consider themselves to be adept programmers and prefer programs that allow them to customize features to their own liking. According to Tripos, there are approximately 10,000 computational specialists (all industries, all applications) worldwide who actively use computer-aided design software in their research activities.

These specialists occupy an awkward role in the wet chemistry hierarchy of pharmaceutical management. Although their value is appreciated, their skills in mathematics, physics and computational simulation are foreign to top R\&D management, which is dominated by organic chemists trained in experimental techniques. As one interviewee stated, "Organic chemists are the demi-gods of pharmaceutical companies. For them, the wet lab is the easiest, cheapest and quickest way to conduct experiments."

The cultural differences can politicize the buying process, prolonging a decision up to a year. Heads of departments using the programs (usually computational chemists) are the key decision makers. Upper R\&D management can become involved, however, depending on the cost of the program. According to one interviewee from a leading pharmaceutical company, "Even though 40 of the top 100 compounds came from modeling, management still does not recognize the value of modeling." Another interviewee stated, "We must always prove that we really need the software."

Key purchasing criteria include ease of use, product support and efficiency. In most instances, price is a secondary consideration. Although some companies stated that they like to purchase programs from academics because they have easy access to the developer and to the source code, most said they preferred to purchase software from commercial companies because of the product support they provide. Operating expenses of the public companies reflect this emphasis on product support. At Tripos and MDL Information Systems, sales, marketing and customer support expenditures represented $47 \%$ and $43 \%$ of 1995 net sales, respectively.

\footnotetext{
${ }^{2}$ Tripos $10-\mathrm{K}$
} 


\section{Product Development}

Throughout the history of pharmaceutical CADD software, academia has played a key role in both developing the more creative software products and in founding the more successful software companies. Amber and Charmm, two well-known programs for empirical force field calculations developed in the early 1980's were written by Peter Kollman at UCSF and Martin Karplus at Harvard, respectively. Oxford Molecular and MSI, respectively, now distribute these programs. An academic, Garland Marshall of the University of Washington, founded Tripos. Bill Goddard at UCSF founded BioSym. People in academia have also started most other companies in the industry. Although MSI, Oxford and Tripos have all expanded from their single product origins, few other companies have achieved the same product success or survived more than a few years.

Commercial companies have depended on academia to grow their business. Rather than creating their own novel software, they license products from academia. Tripos and MDL, for example, spend about $17 \%$ of net sales on R\&D, with much of it concentrated on developing friendly user interfaces, debugging software and interfacing one CADD software program with another. According to Marvin Waldman, Director of Rational Drug Design at Molecular Simulation, these efforts account for a majority of developers' time; only 20 percent of the time is spent developing novel algorithms.

Nurturing these academic relationships is critical to each company's existence, both as a source for new products and for third party validation. The more complex software programs can take up to 3-5 years to develop. The most successful generate revenues of up to $\$ 10-15$ million. To offset the development risk, the major companies have established close working relationships and consulting arrangements with key academics. Companies may fund academics for specific internal projects, or will include them in projects that are jointly funded by the company and the pharmaceutical client.

While academia has been critical to the CADD industry's success, the industry's dependence on academia for new product development has also been its primary failing. Academic grants typically range up to the low six figures, an inconsequential investment given the challenges involved in developing novel software. Compounding academia's inability to effectively respond to these challenges are the growing cutbacks in academic research due to deficit reduction. The CADD industry has tried to make up for academia's financial limitations by forming product development consortia with some of their potential buyers. These companies will advance the developer a fee, allowing them to participate in the product's general design and beta testing. They also get a discount on the released product. Although the concept makes sense, all of the interviewees we spoke with said their experiences in consortia have been mixed. The general complaint is that the developed software suffers from consensus management. It lacks the specificity desired to be of value to any one company, as many companies are not willing to divulge pertinent information about their specific projects. "Every consortium," said one interviewee, "has produced the minimal in everything...The advantages have not outweighed the pain factor." 


\section{A Shifting Focus Away From Structure-Based Design}

The slow pace at which commercial CADD software companies are developing novel programs along with the rapid growth of combinatorial chemistry technologies have shifted the focus of pharmaceutical drug efforts and funding away from structure-based drug design. In recent years, much of the funding that originally had been allocated to develop structure-based drug design technologies has now been designated to developing better combinatorial chemistry techniques and automation technologies. This competition with combinatorial chemistry has produced four trends in the computer-aided drug design industry that promise to have important implications in shaping the industry's future:

- Making programs easier to use rather than better.

- Large, client-specific programs instead of more modest, multi-client (off-the-shelf) software

- Developing programs for information management in preference to molecular modeling

- Alliances instead of acquisitions, particularly between molecular modeling and information management companies.

\section{a. Easier, not better, programs}

Although it is a software business, the risks involved in developing innovative programs for pharmaceutical drug discovery resemble more an investment in the biotech industry than the software industry. Existing programs fall far short of the virtual laboratory envisioned for the industry, but the challenges required to improve them test the theoretical limits about molecular interactions. Expert users complain of these limitations, specifically the inaccuracies of current programs. Significant improvements, however, entail multi-year research projects with no promise of success.

Unwilling to risk their own funds in high-risk (albeit high-return) software projects, industry has chosen to make current programs easier to use instead of better. According to companies we spoke to, the best opportunities for growth were in expanding the number of users. To do so required creating common user interfaces, simpler functions and integrated programs as well as bringing a larger number of capabilities down to the PC level. A wider audience will become introduced to CADD. Whether this will favorably affect research productivity is questionable. As one computational chemist noted, introducing these systems to users that are not familiar with their limitations risks complicating his job, not making it easier.

Tripos and MSI tried to develop and sell code in-house, but realized that this approach was not an efficient use of resources. This trend is documented by the fact that when MSI bought out BioSym, it was the methods development people who were fired and the people who could upgrade codes that remained in the business.

\section{b. Programs for information management instead of molecular modeling}

The rapid growth in combinatorial chemistry and high speed gene sequencing has generated a host of opportunities for information management products. Because these programs offer more immediate financial returns (at less risk), industry has devoted 
diminishing attention to developing improved modeling programs. Growth in the modeling sector has suffered due to the absence of new products and market saturation among expert users. Information management, meanwhile, has quickly become the focus of every company's business plan.

The attention devoted to information management is due to the immediate need for such products as well as industry's opinion regarding the direction of pharmaceutical research. Combinatorial chemistry and high speed gene sequencing are basically automated approaches to the hit-or-miss methodologies that bench researchers are used to. Compared to structure-based approaches, the technologies are readily understandable, ultimately making information management software for the everyday user a much easier sell than modeling programs. More importantly, since it has become faster to generate random leads than to create leads based on an analysis of the target, there is growing opinion that combinatorial approaches will assume a more critical role than structure-based design in pharmaceutical drug discovery (see Section V., "Opportunities in ComputerAided Drug Design").

\section{c. $\quad$ Client-specific instead of multi-client programs}

Organizing consortia to underwrite product development projects has been successful in offsetting risk. According to those who participated in the consortia, however, the results, when there have been any, have been unsatisfying. Recently, Oxford Molecular has tried an approach that is novel to the CADD industry but is commonplace in the biotech industry: instead of working on one project with numerous companies, Oxford has enticed individual companies into multi-year, project-specific development contracts. The contracts are larger, the projects are more focused and, as with the consortium arrangements, Oxford owns the software code and retains rights to sell the software to other companies.

The first contract, signed this past April, was with Yamanouchi, the third largest pharmaceutical company in Japan, to identify small molecules that have a demonstrated activity against ion channels. A team of scientists including representatives from Yamanouchi, Oxford Molecular and the University of Oxford is conducting the research. Yamanouchi has exclusive rights to develop and license compounds discovered during the collaboration. Oxford Molecular receives fees to cover the cost of research and will also receive milestone payments and agreed royalties from the sales of any drugs resulting from the collaboration. The contract is estimated to amount to $\$ 10$ million over three years, the largest contract ever awarded to a CADD company.

In 1995, Oxford entered into an agreement with Glaxo Pharmaceuticals to develop a set of software tools for chemical data analysis. Oxford Molecular has engineers on-site with modelers at Glaxo, who together work with the drug discovery chemists, the ultimate end-users of the product, to develop the software. Each company pays for the personnel they have staffed for the project and shares other development expenses. Other companies may be invited to join in the venture, but only after Glaxo works closely in designing a program that caters to its specific needs. Oxford has said that it expects to sign 1-2 more contracts like these before the end of the year. 


\section{d. $\quad$ Alliances instead of acquisitions}

After years of consolidation, primarily in the molecular modeling segment of the business, the CADD industry has entered into a period of strategic alliances. Most of these alliances are between modeling companies and information management firms. The modeling firms have the software to represent and analyze data. The information management companies have the databases for storing and collecting data. Together, these partnerships aim to create software methodologies for accessing information more efficiently.

Tripos' alliance with MDL is typical of the modeling/information management alliances that have become commonplace in the industry. Tripos, however, has also leveraged its modeling its resources into a valuable service with its alliance with PanLabs. The CADD industry has been trying to broaden its user audience by developing easier-touse programs. Instead of trying to educate an uneducated audience, Tripos generates combinatorial libraries for chemists using its software to define the library's diversity and PanLab's capabilities to synthesize the molecules. The service, introduced early this year, is fast becoming one of Tripos' most important businesses.

Figure 6

\section{Strategic Alliances between CADD Companies (1995-1996)}

\section{Companies}

Tripos \& PanLabs, Inc.

Tripos \& MDL Information Systems

Tripos \& Phase-1 Molecular Toxicology

MDL Information Systems \& Current Science Group (London)

Oxford Molecular \& PE Applied Biosystems

Chemicals Design \& Advanced ChemTech (Louisville, KY)

\section{Purpose of Alliance}

Formed the Tripos Accelerated Discovery Services group to commercialize software for designing chemical compound libraries and managing the data associated with it. Utilizes Tripos' modeling technology and PanLabs' high throughput synthesis methods.

Formed to provide comprehensive solutions in both combinatorial chemistry and molecular design analysis.

Alliance to develop an advanced molecular toxicology database. Uses Phase-1's toxicity assays and Tripos' discovery informatics and high throughput data analysis.

Merger to operate on-line "club" for the world's chemical researchers. Combines chemistry publishing and communications with advanced informatics technologies.

Formed to allow seamless integration and transfer of data between DNA sequencer instruments (Applied Biosystems) and bioinformatics analysis software (Oxford Molecular)

Formed to provide a software interface between Chemical Design's Chem-X product and Advanced ChemTech's Multiple Organic Synthesizers. 


\section{Significant Opportunities Exist for Improved CADD Programs}

The ability of computers to make more than an incremental impact on the drug development process depends on one critical factor: time. Due to rapid advances in automation, more experiments can be performed at a faster pace and lower cost. Computational rates are also increasing at an exponential rate. However, as one interviewee stated, "If computers are increasing in processing speed at a factor of two, automation speed is increasing at a factor of ten."

This race between automation and computational speed has significant implications on the CADD industry. Using combinatorial chemistry, pharmaceutical companies can develop and test millions of compounds cheaply, easily and quickly, potentially significantly shortening the time it takes to produce new therapeutic candidates. For computational structure-based approaches to be effective, they must not only be accurate, but the time and manpower cost to develop an accurate model must be more efficient than the random generation and testing of millions of molecules created using combinatorial techniques.

This element of time only raises the challenge of developing new, more effective molecular modeling software. Molecular modeling occupies an important role in the drug discovery process and a host of opportunities remains unaddressed among the programs currently on the market. Computational chemists complain of the universal lack of accuracy, efficiency and integration in the programs currently available on the market. More accurate programs suggest bigger, more complex - and slower - programs. Scientists we interviewed, however, said repeatedly that even partial solutions to molecular modeling problems would positively affect research productivity and be worth a significant financial premium to pharmaceutical companies.

These unmet needs can be grouped into two categories: scientific and computer-related opportunities. Figure 7 groups these opportunities and quantifies their relative market value. The potential market values listed in the table are derived from the monetary savings that solving each issue would have on certain segments of the pharmaceutical discovery and development process. The values and segmentation structure of the pharmaceutical discovery and development process provided by the Pharmaceutical Research and Manufacturers of America (Figure 8) serve as the basis for the calculations summarized in the table. Note that due to inter-relationships certain opportunities share with others, the market potentials derived here are not additive in their effects on the pharmaceutical industry.

\section{The Scientific Opportunities}

\section{Protein Folding}

The "holy grail" of computer-aided drug design is a software package that designs a drug with optimal binding affinity and therapeutic activity and that predicts how its binding to the therapeutic target is affected by the environment of the human body. Achieving this goal involves understanding the way proteins fold and how their conformation changes as they interact with their environment and bind with a target. Scientists can decipher the order of a protein's linear sequence, but it is the conformation of its complex three- 
dimensional structure in a variety of environments that defines a protein's activity, and that still remains a mystery.

A model that predicted how proteins fold would revolutionize pharmaceutical drug discovery. Knowing the structural characteristics of the therapeutic target, scientists could use a computer to design small molecule or protein drugs that fit exactly into the target site, thus optimizing drug-target binding characteristics and therapeutic efficacy. With the exception of clinical trials, drug development could be reduced to a virtual laboratory, saving companies much of the estimated $\$ 16.5$ billion spent in drug discovery and preclinical development and shaving 2-3 years off the 12 years it now takes to bring a drug to market.

\section{Free Energy of Binding}

Absent an understanding of how proteins fold, scientists have had to resort to timeconsuming and expensive experimental models that approximate ligand-target binding phenomena. These models attempt to determine the free energy of binding, which is the strength of the physical bond between a ligand and a target, and therefore, in effect, to guide scientists towards optimizing the endpoint instead of understanding the process. Although this number can not be directly measured, a number of indirect measurements can be taken experimentally to give a relatively accurate approximation. Several computational products are available that simulate the experimental phenomena behind the measurements. The consensus among those we spoke with, however, was that the software, although put to frequent use, generally either cannot answer the questions scientists would like to pose or were inadequate in the answers they provided.

Figure 8

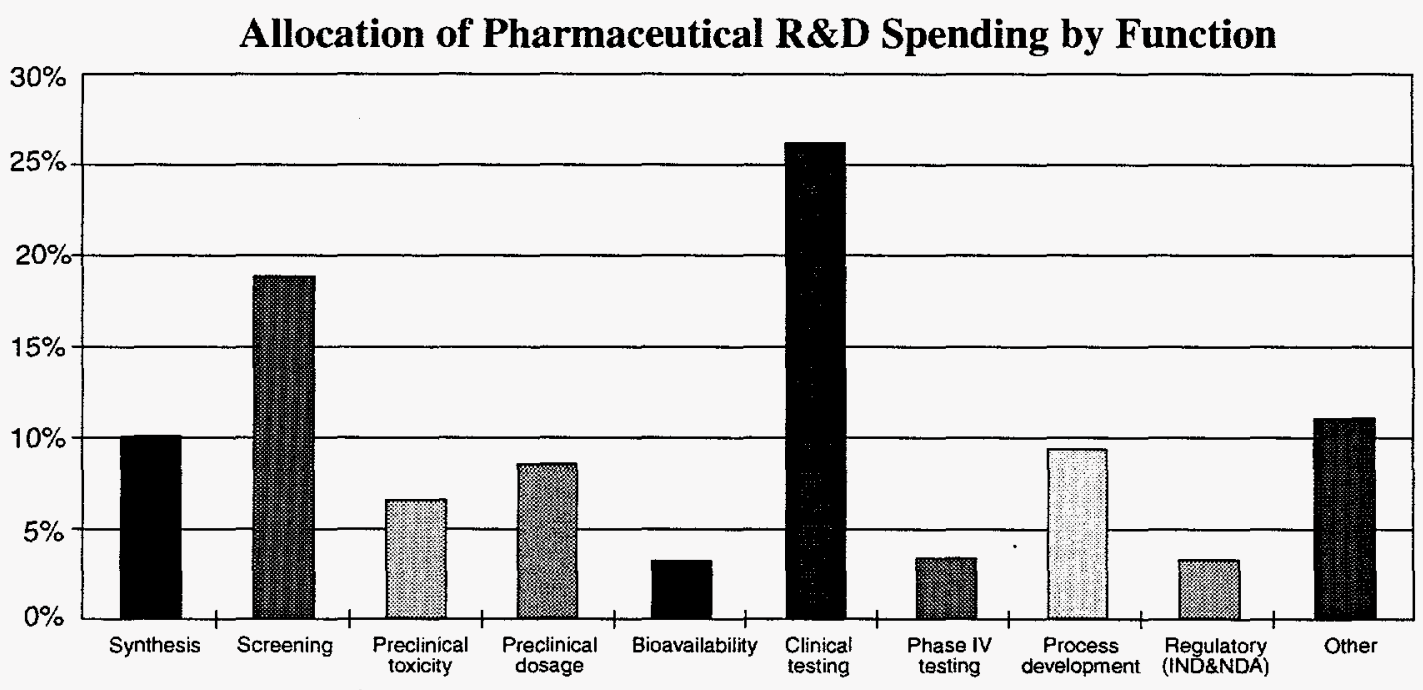

Source: Pharmaceutical Research and Manufacturers Association 
CADD Business Opportunities

\begin{tabular}{|c|c|c|c|}
\hline Opportunity & Description & Potential Market (\$MM) ${ }^{1}$ & Comment \\
\hline $\begin{array}{l}\text { Science Related } \\
\text { - Protein Folding Problem }\end{array}$ & $\begin{array}{l}\text { Understanding how linear amino } \\
\text { acids conform into their three } \\
\text { dimensional structure in a variety } \\
\text { of biological environments }\end{array}$ & $\$ 3,500-4,000$ & $\begin{array}{l}\text { Based on virtual elimination of } \\
\text { drug discovery and screening } \\
\text { ( } \sim 23 \% \text { of pharmaceutical costs })\end{array}$ \\
\hline $\begin{array}{l}\text { - "Multiple Minimum" problem } \\
\text { - Physical relationships } \\
\text { - Free energy } \\
\text { perturbation/molecular } \\
\text { dynamics; quantum } \\
\text { mechanics/electrostatics; } \\
\text { thermodynamics }\end{array}$ & $\begin{array}{l}\text { Eliminating multiple data points } \\
\text { More efficiently solving physics } \\
\text { behind simulating free energy } \\
\text { binding }\end{array}$ & $\begin{array}{c}\$ 500 \\
\$ 1,500-2,000\end{array}$ & $\begin{array}{l}\text { Based on partial elimination of } \\
\text { drug screening } \\
\text { Based on significant elimination of } \\
\text { drug screening }\end{array}$ \\
\hline $\begin{array}{l}\text { - Solvation (pKa)/ } \\
\text { Bioavailability } \\
\text { - Continuous solvation/water } \\
\text { models; metabolism/ } \\
\text { catalysis of ligand }\end{array}$ & $\begin{array}{l}\text { Solving how molecules interact in } \\
\text { solvent/enter bloodstream }\end{array}$ & $\$ 1,000$ & $\begin{array}{l}\text { Based on partial elimination of } \\
\text { bioavailability studies, preclinical } \\
\text { development and drug screening. }\end{array}$ \\
\hline - Toxicology & $\begin{array}{l}\text { Accurately modeling cellular } \\
\text { interactions which may cause toxic } \\
\text { side effects or cell death }\end{array}$ & $\$ 1,250-1,500$ & $\begin{array}{l}\text { Based on partial elimination of } \\
\text { toxicology studies, preclinical } \\
\text { development and screening }\end{array}$ \\
\hline $\begin{array}{l}\text { Flexible structure/chemical } \\
\text { polymorphs } \\
\text { (combinatorial mixtures) } \\
\text { - 3D database design }\end{array}$ & $\begin{array}{l}\text { Resolving minor structure } \\
\text { differences as a result of degrees of } \\
\text { rotation or structural folding from } \\
\text { environment or docking interactions }\end{array}$ & $\$ 500$ & $\begin{array}{l}\text { Based on partial elimination of } \\
\text { several segments of the drug } \\
\text { discovery process. }\end{array}$ \\
\hline
\end{tabular}




\section{CADD Business Opportunities (cont.)}

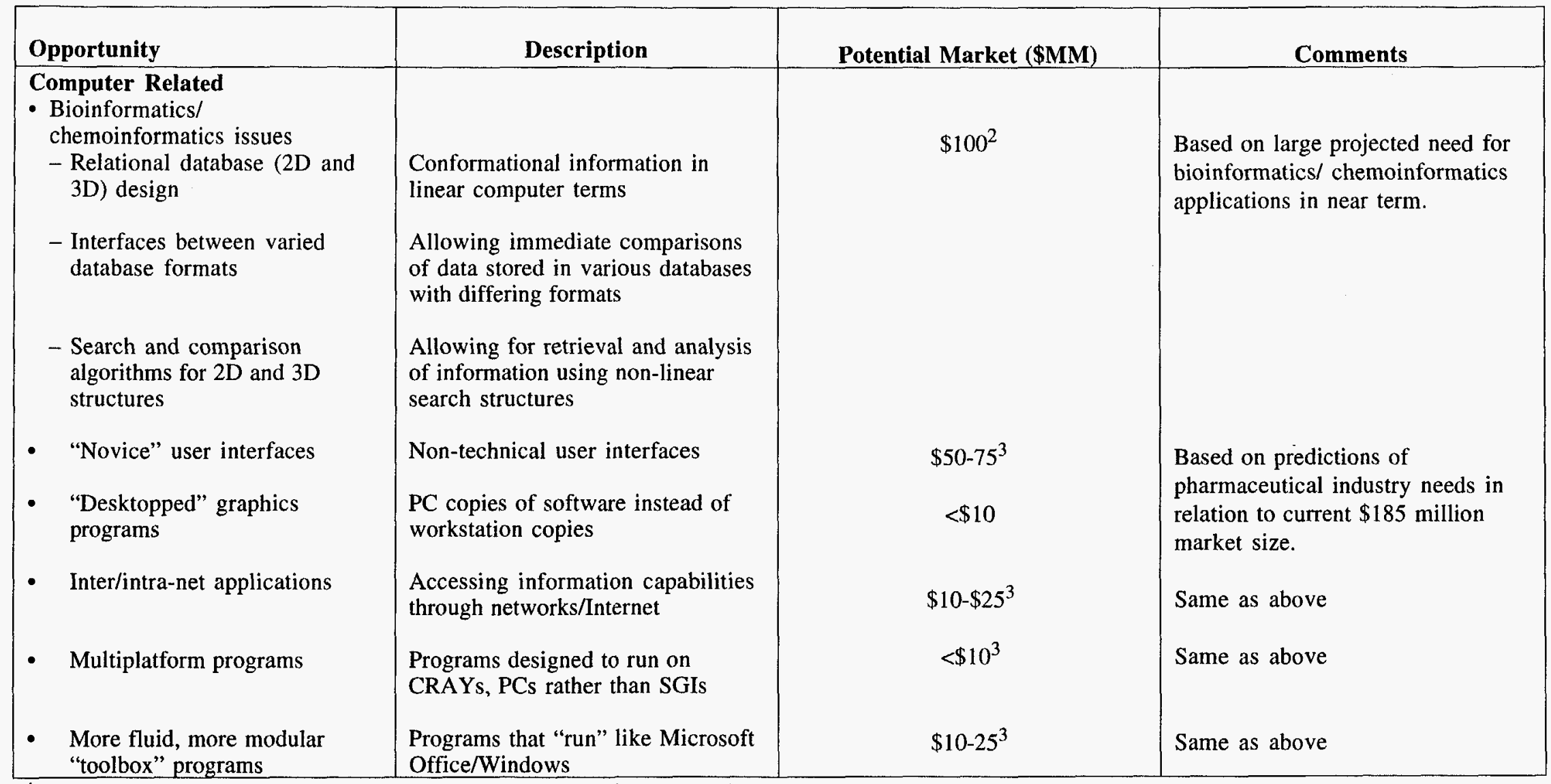

Assumes issue completely resolved and solution methodology validated.

2 Includes the combined opportunity of all three of the database opportunities listed. The potential market value is for the software alone; it does not take into account the additional value of having the software integrated with a proprietary database

3 Incremental "add-ons" to existing programs 
III.

\section{“Multiple Minimum" Problem}

The inadequacies of available programs lie in scientist's poor understanding of the scientific and mathematical processes involved in molecular binding. For example, many of these programs suffer from what is commonly referred to as the "multiple minimum" problem. This mathematical dilemma is due to imperfections in the mathematical functions simulating experimental results, resulting in multiple low-points in the data's graphical representation. This excess "noise" makes the determination of the actual value of the function and its subsequent effect on binding very difficult. Programs which solved this problem would allow scientists to more accurately determine the value of variables involved in binding energetics, enhancing their effectiveness in identifying potential drug candidates

\section{Physics}

The unmet scientific issues can be categorized into three broad areas: physics, bioavailability and toxicology. The physics area, which encompasses topics such as thermodynamics and quantum mechanics, contains the most direct and well-defined problems in molecular modeling, yet these may also be the most difficult to solve. Physicists are constantly refining the functions that describe the physical interactions between two biological molecules and between biological molecules and their environment. Refinements are constrained by the significant gaps that exist in electrostatic theory and other fundamental issues. These constraints reduce the accuracy of such functions, skewing binding energy predictions and limiting their usefulness.

\section{Bioavailability and Toxicology}

The opportunities in the bioavailability and toxicology areas generally lie downstream of the drug discovery process in the drug development and optimization process. Once a drug is selected as a potential therapeutic candidate, scientists seek to optimize its delivery to target tissues while minimizing any inherent adverse effects. Today, bioavailability/toxicology studies are performed as part of a drug's preclinical and clinical studies. With dramatic improvements in software design, however, these studies could be simulated before these expensive studies were begun, avoiding the expense of testing candidates that end up failing FDA standards of tissue penetration, efficacy and toxicity.

Simulating a drug candidate's bioavailability involves modeling both physical and biological events. The physical problem is solvation: namely, how molecules interact with water and other solvent molecules in the human body. This understanding is critical to being able to predict how molecules cross the gut lining and reach their biological target(s). Current models, however, involve highly inaccurate physics functions. Modeling the biological factors affecting bioavailability requires understanding why the body metabolizes some molecules and not others. Currently, there is a lack of statistically significant biological information to achieve dramatic improvements in modeling software. Still, marginal improvements in current software could prove instrumental to developing highly targeted pharmaceutical drugs. 
In terms of toxicology, the issues remain primarily biological in nature. Scientists currently have a limited understanding of what molecules are toxic in what environments and how to predict their toxicity in humans. Models that can predict events such as how molecules react with oncogenes and how they transform innocuous molecules into toxic molecules when bound would be extremely valuable. Scientists could then predict whether the trade-offs between efficacy and toxicity are enough for molecules to survive clinical trials, providing the basis to decide whether to continue clinical development of a drug.

\section{Chemical Polymorphs and the Flexible Structure of Proteins}

Underlying all three of these scientific opportunities are the issues of chemical polymorphs and the flexible structure of proteins. These issues result from two facts: 1) small molecule ligands can have identical chemical formulas but fundamentally different activities due to "minor" variations such as mirror image structures and slightly different angles between bonded atoms; and 2) proteins shift three-dimensional structure when placed in different chemical and biological environments and when bonded to a target. These factors make it difficult for scientists to predict the specific configuration of a given ligand or target in a given environment. Currently, all modeling programs assume that molecules have rigid and fixed configurations. The drawback in such an assumption is that it does not factor in the potential beneficial effects (enhanced binding) or toxicities associated with shifts in a molecule's three-dimensional structure. Such an assumption could prove fatal to predicting a molecule's beneficial or toxic activities and ultimately prevent its widespread use as a drug discovery and development tool.

\section{The Computational Opportunities}

Although less daunting than the hurdles in the scientific and mathematical arenas of molecular modeling, many computer science-related opportunities are no less lucrative. From integrating software across computer platforms to creating more modular "toolbox" applications, the computational needs in molecular modeling are numerous.

\section{Relational Databases}

With the advent of combinatorial chemistry and high throughput genetic sequencing, the amount of chemical and genetic information being generated by science is staggering, and growing at an exponential rate. The amount of information is expected to exceed scientists' ability to process it in the very near future, a problem that will only expand as combinatorial chemistry and high throughput sequencing techniques become perfected. This data output has created a critical, immediate need for databases to store information as well as intelligent search and analysis tools for organizing and retrieving it. Over the next few years, applications will require relational databases with complex, multifaceted structures to contain a wide variety of structural, functional and environmental data derived from combinatorial chemistry and high throughput gene sequencing. Related opportunities involve creating easily searchable database architectures that can hold a large and varied network of two-dimensional and three-dimensional structures and related information. These architectures could contain new scientific methods for more intelligently organizing, grouping and linking related molecular structures and functions. Also important are algorithms for integrating public and private data existing on a wide 
variety of database formats such as GenBank® or Incyte Pharmaceuticals' proprietary LIFESEQ ${ }^{\mathrm{TM}}$ gene sequence database.

\section{Controlled Combinatorial Chemistry Libraries}

There are also opportunities to improve the technology behind combinatorial chemistry. Instead of randomly generating a million molecules with overlapping or unimportant properties, computers are now being designed with algorithms that will optimize combinatorial libraries. These programs will allow researchers to generate controlled libraries containing merely the most diverse set of molecules expressing the properties of interest. The result will be smaller libraries and fewer molecular iterations, ultimately streamlining the timeline for developing drugs based on combinatorial chemistry by several orders of magnitude.

\section{Extension into PCs and the Internet}

The arrival of personal computers into homes and onto every desktop at work open opportunities to expand CADD's use to the everyday chemist or biologist. The programs must be powerful, easy-to-use and able to withstand the rigors of commercial use without requiring the expert "baby-sitting" of current programs. These programs could prove to be important in accelerating the speed and accuracy of a scientist's work by providing an easy simulation alternative to experimental brute force.

Finally, there are Internet and intranet platforms for networking computers to supercomputers and workstations. With these programs, many of which are currently in development, scientists will soon have access not only to public information available on the Internet, but also to other scientists' work and the computational skills of every computer within the same organization or collaborating companies anywhere in the world. By providing such processing and data gathering avenues literally "at their fingertips", these computer programs could free up valuable time for scientists to then devote to analyzing and constructing data.

\section{Four Business Models for Building a CADD Company}

A business involving scientists at the Russian Nuclear Weapons Institute could take one of several forms (Figure 9). None of the businesses are exclusive of one another. All could be part of one business and each could be a stepping stone to the other.

\section{A. Contract Consulting Business}

Forming a company that acts as a contract developer for existing software companies is likely the easiest way to employ the Russian's skills; however, it is clearly the least lucrative. Novel algorithms underlie new product sales. Getting a program sold and used, however, requires a significant amount of user interface design, program integration, sales support, marketing and customer service. Companies spend an estimated $40 \%$ of sales in marketing and sales and $17 \%$ percent of sales in $R \& D$, most of it in refining products. Given these priorities, the Russians would unlikely receive significant returns for their efforts. 
The Russians could enhance their value as contractors by getting involved in interface design and program integration. The problem is that commercial software companies are very protective of their code and likely would only allow such work if the Russians were full time employees or signed exclusive contracts.

Figure 9

\section{Potential Business Models}
Model
Description
Contract Consulting Business
- Develops specialized software on contract for existing commercial companies.
End-user Consulting/Software Business
Off-the-Shelf Software Developer
CADD Service Provider
- Develops client-specific, end-use products. Fully-integrated skills. May or may not retain rights to resell the software to other companies
- Fully-integrated company capable of developing, marketing, selling and servicing software to a broad audience of users. Products may be developed internally or in association with academia or outside providers.
- Develops original software but then markets it as a service to companies instead of selling it as an off-the-shelf package.

\section{B. End-User Consulting/Software Business}

An end-user consulting business is similar to the contract business except that the "client" is the pharmaceutical customer instead of a commercial software developer. There is more value in the model since the "middleman" software company is avoided. Although development costs are more, they can be minimized since customer support, user interface and program integration need apply only to one buyer.

The real upside in such a model is in leveraging the consulting contracts to an offthe-shelf business. Oxford Molecular has demonstrated that the idea can work based on contracts the company has signed with Yamanouchi and Glaxo Wellcome. Although the size of the Glaxo Wellcome contract is unknown, the Yamanouchi agreement is estimated to amount to $\$ 10$ million over three years. In both cases, Oxford Molecular owns the software code and retains rights to resell the software to other users.

Biotech companies have thrived on their ability to negotiate similarly structured agreements with established pharmaceutical manufacturers. Last year the value of these alliances amounted to $\$ 4.8$ billion. Typically, the pharmaceutical company will pay for development costs in exchange for rights to sell the product. The rights may be worldwide or confined to certain geographic segments or therapeutic indications. The biotech company will often receive a royalty on sales, retain manufacturing rights, and/or maintain an option to co-promote the product, if not rights to sell it outright in certain geographic areas. Oxford Molecular's success in extending this concept to software development 
serves as an important business precedent for how to structure a start-up company in the business.

\section{Off-The-Shelf Software Developer}

Today's CADD industry typifies the off-the-shelf business model. As noted elsewhere, costs are heavily skewed to software development instead of product innovation and include a significant investment in marketing and product support. The larger selling programs reach sales of $\$ 10-15$ million. The better companies achieve success by offering a portfolio of software products and catering to a variety of users.

Given the product opportunities available, there is no reason to believe that a company focused on big enough problems could not be significantly larger than MSI, which has sales of $\$ 50$ million and is the largest company in the business. At $\$ 185$ million in industry revenues, the CADD business is barely making a dent in the $\$ 15$ billion spent each year in pharmaceutical research.

\section{CADD Service Provider}

CADD software developers have typically sold their software. An option that has not been pursued, or pursued only with limited success, is providing novel software on a service basis to the pharmaceutical industry. Pharmaceutical companies have outsourced clinical trial management, toxicology services, preclinical laboratory testing and clinical trial management. The concern researchers expressed about outsourcing CADD services were related to confidentiality. Similar to the biotech model, companies could contract for CADD services on a therapeutic area/molecular entity basis. Confidentiality would be no more an issue than it is in a standard biotechnology alliance. Retaining the technology inhouse would also enhance the value of the company and the product development contracts it could negotiate.

\section{A Successful CAD Company Depends on Five Key Factors}

Despite the 30 years it has been in existence, the CADD business is still in its infancy. Programs have been developed that are valuable tools in the research scientist's search for drug candidates. Large problems, however, remain unresolved. Pharmaceutical companies still conduct the bulk of pharmaceutical research using traditional techniques. CADD software has made the tasks easier but new therapeutic molecules still take years to develop and the costs of research and development continue to increase. The CADD business has yet to dramatically improve research efficiency and it is far from revolutionizing the drug discovery process.

Building a successful company to take advantage of these opportunities starts with convincing investors that a company's ambitions can result in significant returns and that its plans for achieving them are credible. The following five key factors are critical to establishing credibility, and hence financing, necessary to fund the business:

- Securing a strong scientific advisory board

- Identifying a large problem with a payoff large enough to offset the risk of investment 
- Validating the Russians capabilities

- Having a strong U.S. administrative base

- Identifying interim project milestones that create value short of $100 \%$ completion

\section{A. $\quad$ Securing a Strong Scientific Advisory Board}

Securing a strong scientific advisory board is not only important in terms of guiding research but also validates a company's business mission. Potential investors need to be assured that the company has identified the right opportunities and is investing its resources appropriately. Having leading scientists overseeing the research provides investors with confidence that the company will appropriately target research.

The SAB should be staffed with recognized leaders in the fields of molecular biology, computational drug discovery, and other relevant skills. The best boards often include Nobel laureates and scientific experts who have credibility both with their scientific peers and with the investment community.

\section{B. Identifying a Large Problem With a Payoff Large Enough to Offset the Risk of Investment.}

Investors do not mind risk as long as it can be justified by appropriate returns. The biggest opportunities in the CADD business test current understanding of biomolecular theory. These are problems that carry the risk of basic research. They are also problems that can potentially result in huge financial rewards.

The likelihood of success and return on investment should be the basis for evaluating projects. The challenge of the problem should not be a consideration as long as the potential for significant financial returns is in line with the investment risk. Money will chase big opportunities as long as the risk is appropriate. The likelihood of success should also not be measured in finding solutions to problems. A company can reap large financial rewards by making significant incremental improvements.

\section{Validating the Russians Capabilities}

Scientists at the Russian Nuclear Weapons Institute are recognized for their skills in modeling nuclear reactions. The value of these skills in developing CADD software, however, has not been tested. The recent agreement with Vertex Pharmaceuticals is an important endorsement from one of the leading biotechnology companies. The Russians need to negotiate additional projects to add further validation that their skills are relevant to CADD software development. Their contributions to each project also need to be significant in order to assure investors that they can solve problems that others cannot.

In addition to demonstrating their skills through projects with the biotech industry, the Russians should also court academia. Most programs have been developed by U.S. academicians. The pharmaceutical industry is well aware of their contribution and looks to academic research to endorse new developments in computer-aided drug design. 


\section{Having a Strong U.S. Administrative Base}

Despite the accomplishments and skills of the scientists in Russia, a critical question remains whether work can be efficiently conducted between two entities thousands of miles apart separated by a language barrier. Even with the breakthroughs in communications technology predicted to occur in the next few years, a strong United States presence will be necessary to allay industry fears that distance and language outweigh the Russian's skills.

This presence must consist of a talented management team that can mediate interactions between the Russians and United States companies and be responsible for new business, customer service, and sales and marketing. The quality of the management team will be crucial to raising the necessary monies to fund the company as well as the company's eventual success.

\section{E. Identifying interim project milestones that create value short of $100 \%$ completion}

Many of the opportunities outlined in this report are difficult issues that may take a large commitment of time and financial resources to complete regardless of the skill level of the scientists performing the research. Investors need to have a measurable way to evaluate progress and gauge the value of their investment. Identifying interim milestones that are aggressive but achievable can best achieve this objective. These milestones serve to benchmark expectations. When achieved, they can serve as news events for communicating the company's value as well as accomplishments the company can point to when raising additional financing.

\section{Conclusions}

There is tremendous demand in the pharmaceutical industry for technology that increases the efficiency of the drug discovery process. Industry spending on drug discovery has been increasing steadily without a commensurate increase in new pharmaceuticals approved for marketing; thus, discovery productivity has actually gone down over the past decade. Over the past ten years, virtually every large pharmaceutical company has made substantial investments in external technology that will enhance its discovery capability. The size and frequency of these investments continues to increase as companies compete to discover innovative products.

CADD software has shown great promise as a technology but so far has assumed a relative minor role in the drug discovery process. Current industry revenues are less than $\$ 200$ million in the aggregate, and pharmaceutical companies have turned to other approaches, such as combinatorial chemistry and high throughput screening, to speed the drug discovery process. We believe this failure has been due to the CADD software industry's failure to develop truly effective products that meet the pharmaceutical industry's needs. The vast majority of CADD products were developed by academics and many are over 10 years old. CADD industry spending on R \& D amounts to only $17 \%$ of revenues and much of this investment is spent on modifying existing products versus true innovation. 
As a result, there is tremendous unmet demand for truly effective CADD products. In order to exploit the market opportunity in CADD, scientists at the Russian Nuclear Weapons Institute should proceed as follows:

- Secure a strong Scientific Advisory Board from which a knowledge of biology and the marketplace can be derived;

- Pursue truly important CADD problems that address large potential markets and where the payoffs are sufficient to offset the investment risk;

- Establish operations in the U.S. in order to facilitate liaison with the pharmaceutical research community and access to the U.S. public equity markets;

- Validate capabilities by negotiating additional contracts with the biotechnology industry similar to the one recently negotiated with Vertex Pharmaceuticals;

- Design projects to meet important milestones well short of completion in order to facilitate external validation and financing; 
Appendix A: Methodology 
Appendix A

\section{Research Methodology}

Kendall Strategies completed twenty-two interviews with users and developers of CADD software (Table A-1). In addition to the interviews, Kendall completed a review of the secondary research on the CADD industry and attended the annual meeting of the American Chemical Society. Most of the CADD companies exhibited at the ACS meeting, providing an opportunity to talk with a number of company representatives about product and technology trends in the industry.

The interviews were conducted either in person or by phone. The interviewees were typically senior scientists at four types of institutions:

No. of Interviews

- Pharmaceutical Companies

- Biotechnology Companies

6

- Commercial Software Companies

9

- Academia/Government Organizations

Total

27

Most of interviewees had backgrounds in either computational chemistry or structural biology. One (G. Verkhivker, Agouron) was a Russian physicist.

Interviewees were identified through Kendall Strategies' contacts in the biotechnology research industry and through referrals. Each interview lasted approximately one hour and covered several key topics:

- Definition of the CADD Business

- Market Dynamics

- Current Products

- Product Development Trends

- Purchasing Decision Making

- Significant Unmet Needs and Potential Value 
Table A-1

\section{Completed Interviews}

\section{Name/Title}

Jeff Blaney, Ph.D.

Director of Computational and

Biophysical Chemistry

Eric Martin, Ph.D.

Sr. Scientist

Roger Critchlow, Ph.D.

Sr. Computational Chemist

Frank Brown, Ph.D.

Executive Group Director-

Chemoinformatics

J. Scott Dixon, Ph.D.

Associate Director

Physical and Structural Chemistry

Richard J. Feldman

Computer Specialist

Laboratory of Structural Biology

Dr. Yuri Sergiev

Chris Fields, Ph.D.

VP, Scientific Affairs

Richard Freisner, Ph.D.

Professor of Chemistry

Angel Garcia, Ph.D.

\section{Affiliation}

Chiron Corporation

4560 Horton Street

Emeryville, CA 94608

(510) 601-3319
Date/Location

7/31/96 at Chiron
Oxford Molecular Group

1610 Claymore Drive

Chapel Hill, NC 27516

(919) 968-8815

SmithKline Beecham

709 Swedeland Road

King of Prussia, PA 19406

(610) 270-4293

National Institutes of Health

Division of Computer Research and

Technology

Building 12 A, Room 2045

Bethesda, MD 20892-5626

(301) 496-1100

Molecular Informatics

1800 Old Pecos Trail

Santa Fe, NM 87505

(505) $982-7840$

Department of Chemistry

Columbia University

New York, NY 10027

(212) 854-7606

Los Alamos National Laboratories

T-10 Mail Stop K710

Los Alamos, NM 87545

(505) 665-5341
7/31/96 at Molecular Informatics

$8 / 20 / 96$ by phone

8/30/96 by phone

$8 / 20 / 96$ by phone

9/3/96 by phone

8/2/96 at LANL 


\section{Completed Interviews (cont.)}

\begin{tabular}{|c|c|c|}
\hline Name/Title & Affiliation & Date/Location \\
\hline $\begin{array}{l}\text { Jonathon Greer, Ph.D. } \\
\text { Senior Project Leader } \\
\text { Department of Structural Biology }\end{array}$ & $\begin{array}{l}\text { Abbott Laboratories } \\
\text { Building AP10 } \\
100 \text { Abbott Park Road } \\
\text { Abbott Park, IL 60064-3500 } \\
\text { (847) 937-6933 }\end{array}$ & $8 / 20 / 96$ by phone \\
\hline $\begin{array}{l}\text { Timothy Havel, Ph.D. } \\
\text { Lecturer }\end{array}$ & $\begin{array}{l}\text { Harvard Medical School } \\
\text { Dept. of Biological Chemistry and } \\
\text { Molecular Pharmacology } \\
240 \text { Longwood Avenue } \\
\text { Boston, MA 02115 } \\
\text { (617) 432-3242 }\end{array}$ & 9/29 at Harvard \\
\hline $\begin{array}{l}\text { Barry Honig, Ph.D. } \\
\text { Professor, Biochemistry \& } \\
\text { Molecular Biophysics }\end{array}$ & $\begin{array}{l}\text { Columbia University } \\
\text { Black Building - Rm. } 221 . \\
\text { New York, NY } 10027 \\
\text { (212) } 305-7970\end{array}$ & $8 / 13 / 96$ by phone \\
\hline Richard Judson, Ph.D. & $\begin{array}{l}\text { Sandia National Laboratory } \\
\text { Mail Stop 9214, P.O. Box } 969 \\
\text { Livermore, CA } 94511-0969 \\
(510) 294-1438\end{array}$ & $8 / 23 / 96$ by phone \\
\hline $\begin{array}{l}\text { Irwin Kuntz, Ph.D. } \\
\text { Professor of Pharm Chemistry }\end{array}$ & $\begin{array}{l}\text { Univ. of California Medical Center } \\
505 \text { Parnassus Avenue } \\
\text { San Francisco, CA } 94143 \\
\text { (415) } 476-1937\end{array}$ & $8 / 20 / 96$ by phone \\
\hline $\begin{array}{l}\text { George Lauri } \\
\text { Computer Scientist }\end{array}$ & $\begin{array}{l}\text { Pharmacopeia, Inc. } \\
101 \text { College Road East } \\
\text { Princeton, NJ } 08540 \\
(609) 452-3756\end{array}$ & $9 / 4 / 96$ by phone \\
\hline $\begin{array}{l}\text { Robert MacDowell, Ph.D. } \\
\text { Senior Scientist }\end{array}$ & $\begin{array}{l}\text { Genentech, Inc. } \\
460 \text { Pt. San Bruno Blvd. } \\
\text { S. San Francisco, CA } 94080 \\
\text { (415) } 225-1000 \text { X2271 }\end{array}$ & 7/30/96 at Genentech \\
\hline $\begin{array}{l}\text { Gerald Maggiora, Ph.D. } \\
\text { Director of Molecular Modeling }\end{array}$ & $\begin{array}{l}\text { Pharmacia \& Upjohn Inc. } \\
700 \text { Portage Road } \\
\text { Kalamazoo, MI } 49001 \\
\text { (616) } 833-9350\end{array}$ & $8 / 20 / 96$ by phone \\
\hline $\begin{array}{l}\text { Brian Masek, Ph.D. } \\
\text { Section Manager } \\
\text { Structural Chemicals }\end{array}$ & $\begin{array}{l}\text { Zeneca Corporation } \\
1800 \text { Concord Pike } \\
\text { Wilmington, DE } 19850 \\
(302) 886-2114\end{array}$ & $8 / 22 / 96$ by phone \\
\hline
\end{tabular}




\section{Completed Interviews (cont.)}

\begin{tabular}{|c|c|c|}
\hline Name/Title & Affiliation & Date/Location \\
\hline James McGinity, Ph.D. & College of Pharmacy & $9 / 29$ by phone \\
\hline Professor & Univ. of Texas at Austin & \\
\hline Director of Drug Dynamics Institute & $\begin{array}{l}\text { Austin, TX 78712-1074 } \\
\text { (512) } 471-4843\end{array}$ & \\
\hline $\begin{array}{l}\text { Mark Murcko, Ph.D. } \\
\text { Senior Scientist }\end{array}$ & $\begin{array}{l}\text { Vertex Pharmaceuticals } \\
40 \text { Allston Street } \\
\text { Cambridge, MA 02139-4211 } \\
\text { (617) 576-3111 }\end{array}$ & $7 / 17 / 96$ at Vertex \\
\hline $\begin{array}{l}\text { Barry Robson } \\
\text { Chief Scientific Officer }\end{array}$ & $\begin{array}{l}\text { Gryphon Sciences } \\
250 \text { East Grand Avenue, Suite } 90 \\
\text { South San Francisco, CA } 94080 \\
\text { (415) } 885-7410\end{array}$ & $8 / 27 / 96$ by phone \\
\hline Paul Scharifson, Ph.D. & $\begin{array}{l}\text { Glaxo Wellcome } \\
\text { Five Moore Road, Box } 13398 \\
\text { Research Triangle Park, NC } 27709 \\
\text { (919) 483-1288 }\end{array}$ & $8 / 22 / 96$ by phone \\
\hline $\begin{array}{l}\text { Gennady Verkhivker, Ph.D. } \\
\text { Senior Scientist }\end{array}$ & $\begin{array}{l}\text { Agouron Pharmaceuticals, Inc. } \\
10350 \text { N. Torrey Pines Rd. } \\
\text { LaJolla, CA } 92037 \\
\text { (619) 622-3008 }\end{array}$ & 7/31/96 at Agouron \\
\hline $\begin{array}{l}\text { Marvin Waldman, Ph.D. } \\
\text { Director, Rational Drug Design }\end{array}$ & $\begin{array}{l}\text { Molecular Simulations Inc. } \\
9685 \text { Scranton Road } \\
\text { San Diego, CA 92121-3752 } \\
\text { (619) 546-5302 }\end{array}$ & $7 / 31 / 96$ at $\mathrm{MSI}$ \\
\hline $\begin{array}{l}\text { Dave Weininger, Ph.D. } \\
\text { President }\end{array}$ & $\begin{array}{l}\text { Daylight Chemical Information Systems, } \\
\text { Inc. } \\
419 \text { E. Palace Ave. Suite } 1 \\
\text { Santa Fe, NM } 87501 \\
\text { (505) } 989-1000\end{array}$ & $8 / 1 / 96$ at Daylight \\
\hline Hershel Weintraub, Ph.D. & $\begin{array}{l}\text { Johnson \& Johnson } \\
\text { Route 202, P.O. Box } 300 \\
\text { Raritan, NJ 08869-0602 } \\
(908) 704-5835 \\
\end{array}$ & $8 / 22 / 96$ by phone \\
\hline
\end{tabular}


Appendix B: Major Competitors 


\section{Appendix B}

\section{Chemical Design Holdings}

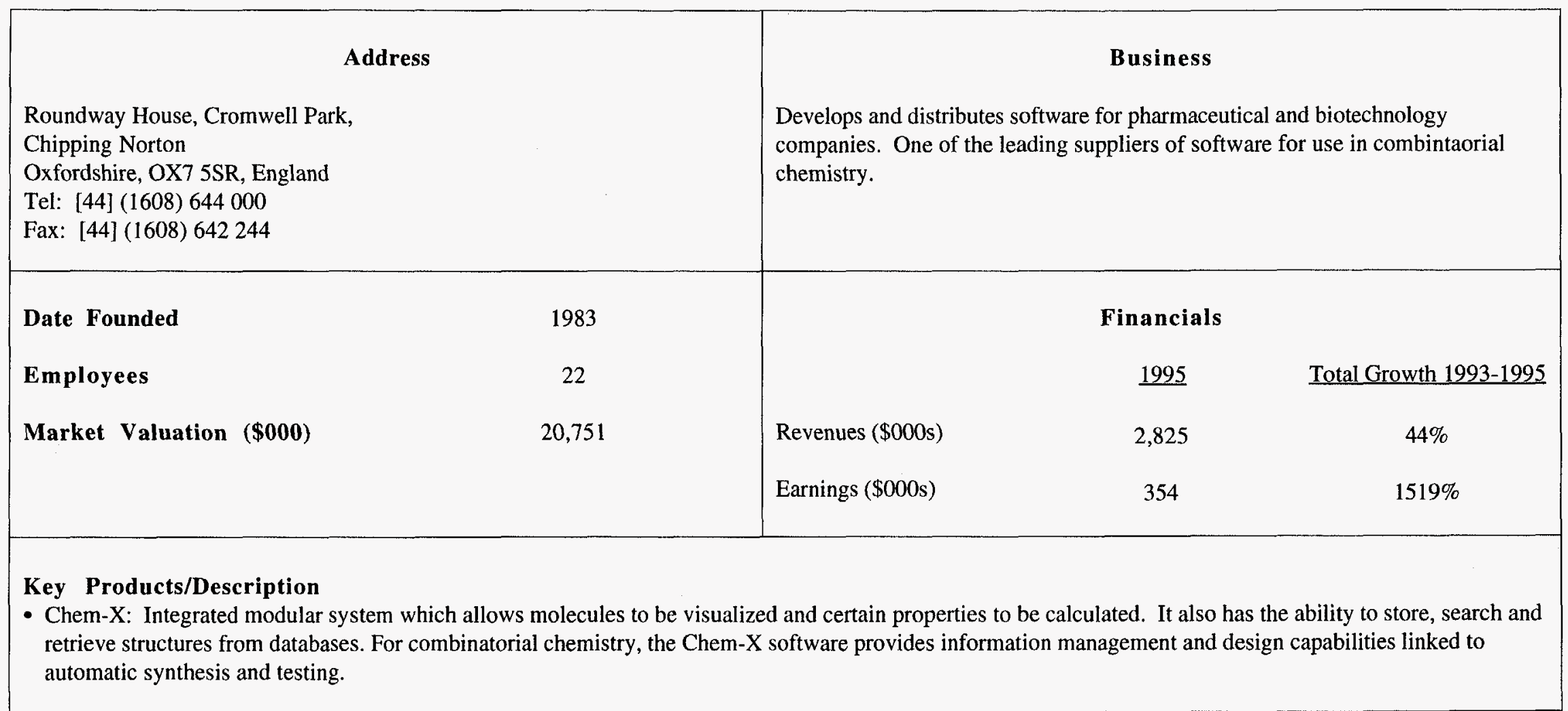




\section{Appendix B}

\section{Chemical Design Holdings (continued)}

\section{Recent News/Alliances}

- Alliance with ChemBridge Corporation to develop DIVERSet, a diverse set of compounds specifically designed for use in High Throughput Screening programs. The product is marketed both by Chemical Design and by ChemBridge (1995).

- Alliance with Advanced ChemTech (Louisville, KY) to provide a software interface between Chem-X and Advanced ChemTech's Multiple Organic Synthesizers (1996).

- Introduced HTS Chemicals CD-ROM in collaboration with chemical suppliers and manufacturers. Product provides a list of suppliers' databases on CD-ROM and is available for subscription from Chemical Design with a quarterly update release schedule.

* Conversion from Pounds to Dollars based on $1 £=\$ 1.56$. 


\section{Appendix B}

\section{Information Systems, Inc.}

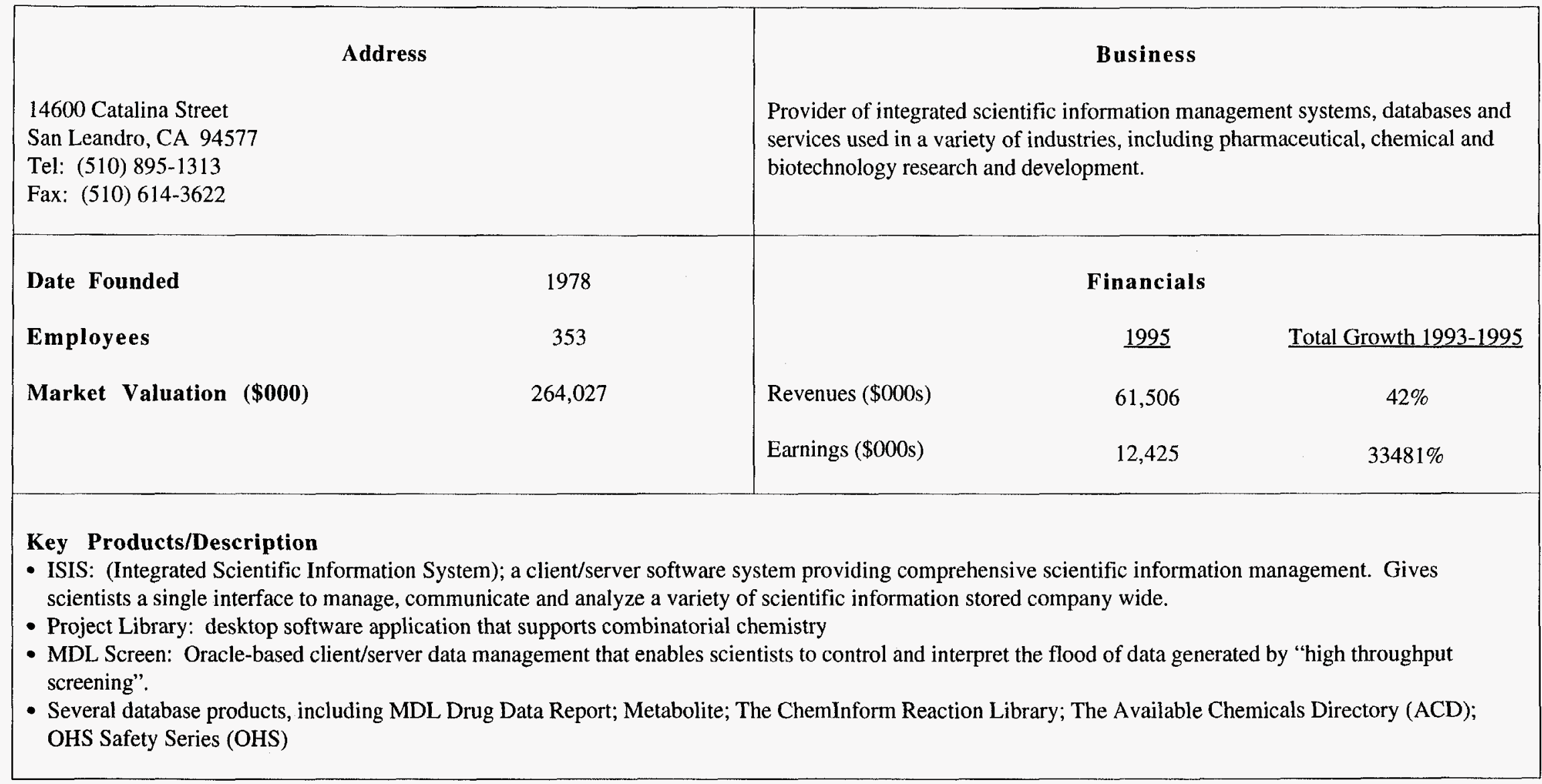




\section{Appendix B}

\section{Information Systems, Inc. (continued)}

\section{Recent News/Alliances}

- Alliance with Tripos to provide comprehensive solutions in both combinatorial chemistry and molecular design analysis (1996).

- Joint venture with Current Science Group (London) to operate an on-line "club" for the world's chemical researchers. New company will be called ChemWeb and will build and market the first World Wide Web site that combines a wide range of chemistry publishing and communications with advance informatics technologies that speed access to research data (1995).

- Entered strategic alliances with five robotics companies to support high throughput screening efforts. Companies include ROBOCON, SAGIAN Inc., Scitec

Laboratory Automation, Tomtec Inc., and Zymark Corporation (1995).

- Agreement with Fachinformationszentrum Chemie GmbH (FIZ CHEMIE Berlin) to produce Solid-Phase Organic Reactions (SPORE), a new reaction database covering solid-phase organic methodology. 


\section{Appendix B}

\section{Molecular Simulations, Inc.}

\begin{tabular}{|c|c|c|}
\hline \multicolumn{2}{|l|}{$\begin{array}{l}9685 \text { Scranton Road } \\
\text { San Diego, CA } 92121-3752 \\
\text { Tel: (619) 458-9990 } \\
\text { Fax: (619) 458-0136 }\end{array}$} & $\begin{array}{l}\qquad \text { Business } \\
\text { Provides computational chemistry software to scientists, experimentalists and } \\
\text { engineers to organize scientific data, share information and develop, analyze and } \\
\text { simulate novel compounds and processes. }\end{array}$ \\
\hline $\begin{array}{l}\text { Date Founded } \\
\text { Employees } \\
\text { Market Valuation }(\$ 000)\end{array}$ & $\begin{array}{l}1984 \\
260 \\
\text { NA }\end{array}$ & $\begin{array}{c}\text { Financials } \\
\underline{1995} \\
50 \text { (approx.) } \\
\text { NA }\end{array}$ \\
\hline \multicolumn{3}{|c|}{$\begin{array}{l}\text { Key Products/Description } \\
\text { - Cerius²: comprehensive modeling environment for building, editing and visualizing models of molecular structures. Users plug software to build a completely } \\
\text { integrated package tailored to specific research needs utilizing both external and in-house databases. } \\
\text { - Insight II: 3D graphical molecular modeling environment with seamless interface between other MSI programs allowing creation, modification, manipulation, } \\
\text { display and analysis of molecular systems and related data. } \\
\text { - QUANTA: comprehensive modeling environment for 2D and 3D modeling, simulation and analysis of macromolecules and small organics, including } \\
\text { structural and similarity analysis, cluster analysis and flexible fitting. } \\
\text { - Protein Workbench: tools for protein structure determination, analysis and refinement, including homology modeling and secondary structure prediction. } \\
\text { - NMR Workbench: Integrated system combining advanced modeling methods with interactive, multi-dimensional processing and analysis of NMR spectra. } \\
\text { energy minimization to solve 3D molecular structures. }\end{array}$} \\
\hline
\end{tabular}


Appendix B

\section{Molecular Simulations, Inc. (continued)}

Recent News/Alliances

- Started Combinatorial Chemistry Consortium to address the entire scope of the combinatorial chemistry process. The key objectives are to create UNIX and desktop combinatorial chemistry software packages that share common computational servers based upon Cerius ${ }^{2}$.

- Currently running a worldwide seminar series on combinatorial chemistry with IBM. 


\section{Appendix B}

\section{Oxford Molecular Group PLC}

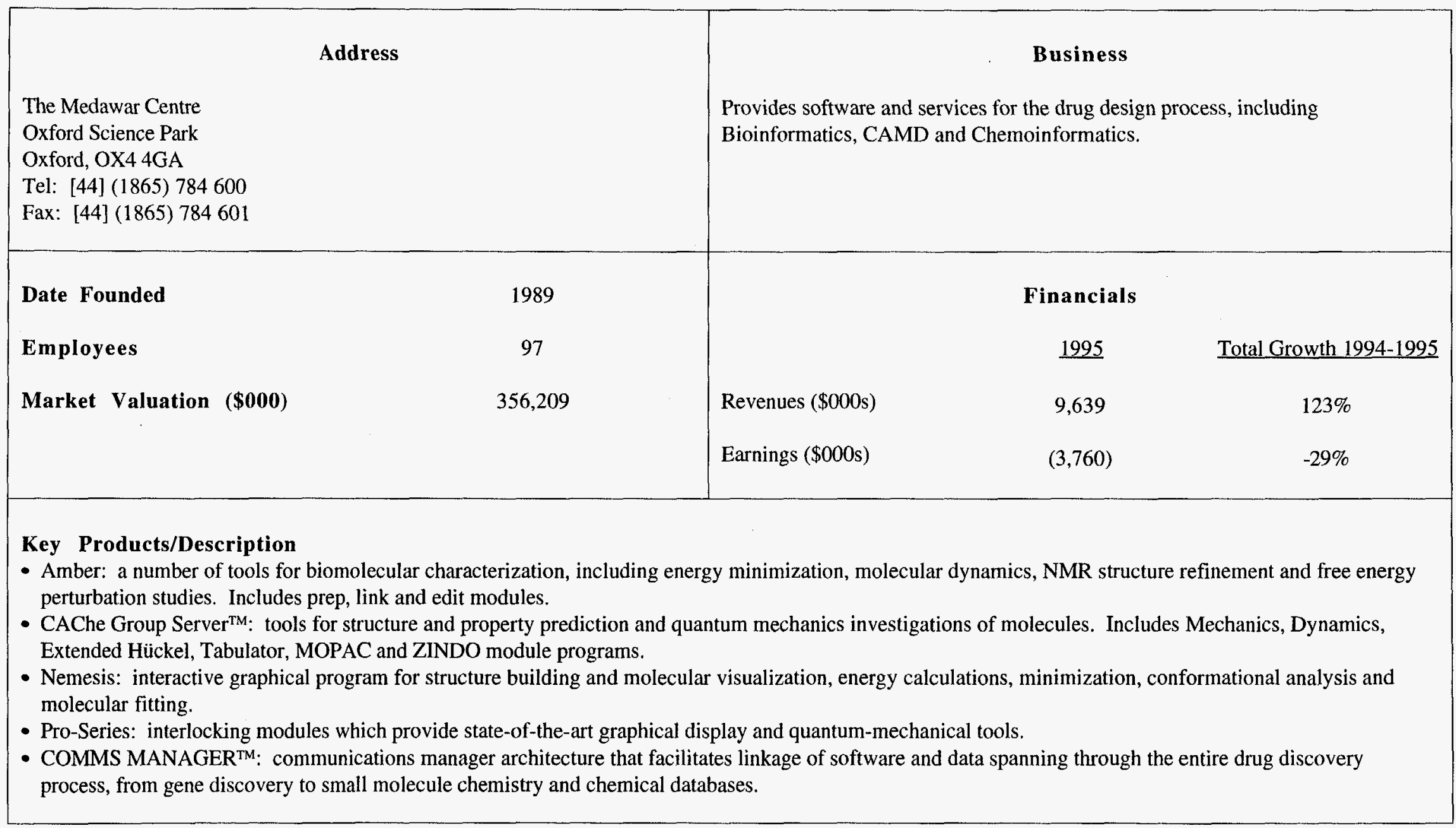




\section{Appendix B}

\section{Oxford Molecular Group PLC (continued)}

\section{Recent News/Alliances}

- Completed several acquisitions in 1996:

- DPS Acquisition Company from Cray Research. Agreement includes UniChem, quantum mechanic design tool for Cray Supercomputer. Product and associated support generated $\$ 1.1$ million in revenues in 1995.

- Chemical Information Division (CID) of PSI International. Includes three major products: RS $^{3}$ Discovery (relational database); Kekule (chemical structure drawing tool); and CIS (on-line chemical information services). CID 1995 revenues totaled approximately $\$ 1.52$ million.

- MacVector Business of Eastman Kodak. Products include protein sequence analysis software for the bioinformatics sector. Revenues were estimated at $\$ 1$ million.

- Health Designs Inc. (HDI). Leading commercial suppliers of computer-aided toxicology prediction software.

- Entered into project-specific research development contracts with large pharmaceutical companies:

- Yamanouchi for work in the study of ion channels

- Alizyme for work in the study of obesity

* Conversion from Pounds to Dollars based on $1 £=\$ 1.56$. 


\section{Appendix B}

\section{Tripos, Inc.}

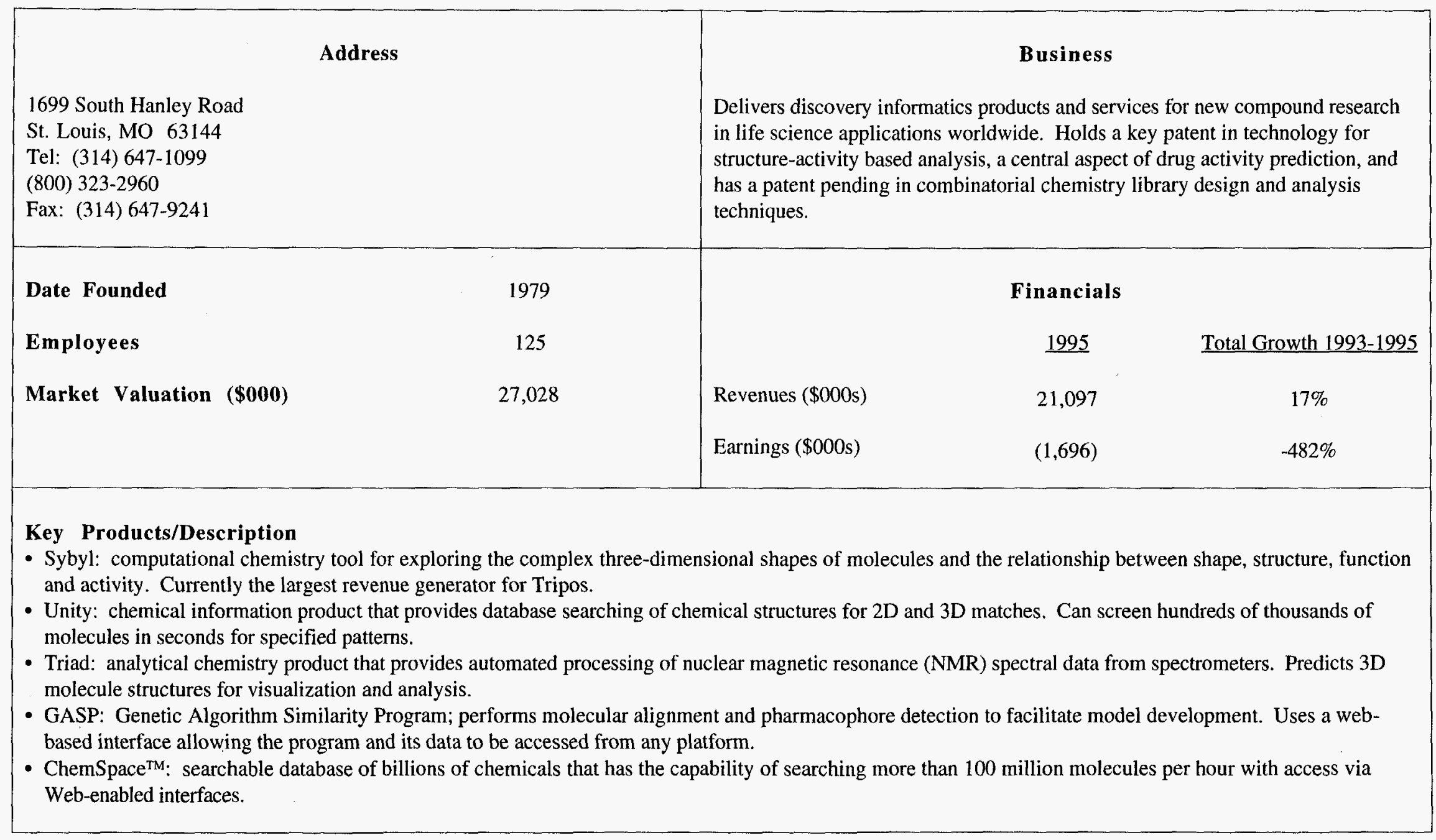




\section{Appendix B}

\section{Tripos, Inc. (continued)}

\section{Recent News/Alliances}

- Alliance with Panlabs, Inc. to form Tripos Accelerated Discovery Services group. Uses Tripos' proprietary software to conduct research and develop compounds and uses Panlabs' high throughput synthesis methods. Group has its own sales/marketing team (1996).

- Alliance with MDL Information Systems to provide comprehensive solutions in both combinatorial chemistry and molecular design analysis (1996).

- Invested in Phase-1 Molecular Toxicology (Santa Fe, NM). Will combine Tripos' discovery informatics and high throughput data analysis with Phase-1's toxicity assays to develop an advanced molecular toxicology database. 
Appendix C: Interview Notes 


\section{Jeff Blaney, Eric Martin, Roger Critchlow \\ Chiron Corporation \\ July 31, 1996}

- Chiron involved in therapeutics discovery; 50 people dedicated to discovery of small organic molecules; Amgen is just now getting into this

- Chiron has 5 people involved in computational chemistry

- Designing approaches for optimal libraries

- Structure-based design - structural knowledge of receptor structure

- Would add a category to the three categories of modeling (visualization systems; simulation; molecular modeling): would add prediction, which is a stand alone category...combines all three of the above...uses tools to do analysis of molecules... structure already exists

- Tools available for all three categories...tools for prediction category include interactive graphic system; genetic algorithms...challenge is "what is your scoring function"?

- Structure-based design is a simulation problem

- Similarity: construct mathematical model to predict structure

- Molecular similarity: structure is known..invent a molecule's activity

- Sampling of organic chemistry is infinite

- Any algorithm sampling is only a tiny part of the system

- Most companies have several programs in simulation \& visualization

- "Good predictive software requires optimizing the rules of chemistry"

- There are two approaches: given structure you predict activity; the other is to characterize activity and use this to design a structure. The latter is what people really want.

- Real challenge is computing the force between ligand and receptor

- Reproducing energies of how tightly one molecule is bound to another is challenging

- Problem with simulation....water molecules could move anywhere. With water you must simulate the interaction; the main component is entropy. Nobody has figured out how to model water. The theory is worked out but if you applied it in a model the model would become too large and long.

- Free energy perturbation relies on simulation methods...underlying physics not well captured

- To be able to take ligands and say which will bind to receptors would be valuable..a lot of research in this area right now

- A lot of effort put into binding affinity

- Weakness in computational chemistry..optimization methods...don't have people paying much attention to it

- It used to be that solving the structure was enough. Then it was thought that getting the crystal structure of the binding site would be enough. This still doesn't suggest activity.

- New models for solvation...most computational chemists not good mathematicians

- We lack good optimization models. A lot of what Blaney's group does is optimization

- 3D database...flexible molecules always dealt with in sampling conformations...many conformations

- Need more abstract ways to describe molecules to create more selective libraries

- Nussanav - IBM - geometric hashing algorithms

- Commercial tools for 3D database searching --torsion-based optimization...Tripos product ("directed Tweek(?) algorithm), MSI, Molecular Design

- Question is the molecule redundant with another molecule or do they have unique properties?

- The question is what is the ensemble of conformations represented by a molecule? Most of what we d is simply take some internal constraints within the molecule and push them around. 
- Upjohn - Gerry Maggiora; has focus on molecular similarity

- Professor Thomas Lozano - MIT/Artificial Intelligence lab; has done work with Aries

- Gap between what they do and what we do is pretty large

- DIMAX- Discrete \& Applied Mathematics at Rutgers

- IMA - University of Minnesota at Minneapolis; runs workshops in different areas of computational mathematics

- Need specific models to deal with water in one field versus another field

- Need to have a lot of interaction in communicating these issues to a third party...communication a problem

- Simulation/Molecular similarity...initially would require a lot of interaction

- Physicists/mathematicians deal with empirical reality in a pure way

- Computational chemists deal with empirical reality in an impure way

- Book to look at that summarizes key issues: "Reviews in Computational Chemistry" -Donald Boyd; Kenny Lipkowitz

- Richard Judson - San Dia Livermore - 45 minutes from Oakland...chemical physicist....weapons related theoretical calculations...CRADA industry grant

- New problem in combinatorial chemistry: now possible to make mixtures of compounds more quickly than make one compound...don't know what to do with the data...don't know what to do when sample of 1000 molecule mixture. Would like to evaluate activities of mixtures; this would be very efficient.

- If 1000 molecules are inactive..then is there a $90 \%$ chance that the individual molecules are inactive?

- Given a mixture of " $n$ " molecules: would like to know what are the active individual compounds?...simulation models weighing which mixtures to go to first and what are the active ingredients

- Programs cost anywhere from $\$ 10,000$ to $\$ 100,000$

- Approach to handling combinatorial mixtures -- attractive to pharmaceutical companies, biotech companies, and agra-pharma companies

- People in these biotech companies rarely produce code that are for commercial value

- In each of the major companies, people will be inventing their own tools

- Oxford Molecular -- They improve programs to make them more robust and easier to use

- CompuDrug -- Budapest and Rochester (U.S.); selling proprietary computation software..working with Chiron...designing expert systems for predicting metabolism

- Daylight Chemical Information Systems - Santa Fe...clever algorithmic people; Dave Weininger (505) 988-7394; (505) 989-1000; prime force between a loose consortium of companies...Chemical Information Exchange Consortium...to produce commercial quality software but not for distribution...people contribute different ideas and codes 


\section{Frank Brown \\ Oxford Molecular Group \\ August 20, 1996}

- He is executive group director at Oxford Molecular (similar position in the U.S. would be Executive Vice President - Business Development)

- 132 total employees, 50 in the U.S. -- growing towards 150

- Question you need to ask is what role do these programs play in the drug discovery process? Primary goal for pharma companies is target identification: find, optimize and develop leads

- Believes visualization/simulation/similarity are too narrow...these are really three different categories within optimization

- Optimization currently not mature for desktop

- Visualization/graphics are desktop (Rasmal)..this is a mature segment of the industry

- 3D/stereo viewing -- specialized rooms for viewing, discussion..20-30 people can see the program at one time

- Supported by 10 people in the company right now

- Sequence alignment is a general problem/docking is not general

- $\$ 100-\$ 120$ million in software sales is accurate

- Many of these companies base revenue calculations on hardware sales projections

- Molecular Design Ltd. is delivering solutions for 3D databasing

- Of the three modeling categories, visualization is generally the highest revenue producing...its actual sales are small, but it is the catalyst for the purchase of other products

- EXPLOR - simulation program, does well

- He believes in the future it is similarity that will drive revenue

- Bioinformatics defined as genomics, genetics...they just hired leading physician in bioinformatics

- What the world needs is a good method of sifting through the data...so much money is spent on designing the drugs that with the onset of combinatorial chemistry we need to have a good way of sifting through the data

- Chemoinformatics defined as combinatorial chemistry, high throughput screening

- Oxford Molecular will introduce chemoinformatics product at ACS showing next week

- All of the problems with visualization/simulation/similarity have to do with ease of use...getting away from focusing on accuracy, efficiency

- Oxford Molecular has grown through acquisition of products

- Currently focusing on marketing to overcome the perception that they are just a distributorship for academic software

- Oxford Molecular not really focusing on optimization, but rather on chemoinformatics and bioinformatics

- "World does not need another simulation program"

- Oxford has agreement with Glaxo to work with experimentalists/scientists...very good way of validation

- Revaluation will be big method of sale in the future

- Shifting towards Java computers

- Future will be a "Microsoft Office" type of user interface...different modules that will have the look and feel of one program

- Purchasing decisions within companies is highly political...scientists will usually makes the decisions, not the IT people (but they may be scientists within the IT group)

- Don't have standard interfaces yet

- Oxford Molecular moving to be a provider of complete solutions

- Would not discuss whether they like to sell on a per site or per seat basis 


\section{Scott Dixon \\ Smith Kline Beecham \\ September 3, 1996}

- He who solves protein folding would "win Nobel Prize shortly thereafter"

- NIH "Grand Challenge" Problem -- is it worth it?

- Computation must be comparable to "cost" of wet lab data in terms of time, cost, etc....shorter due to advents in robotics, automation

- Rise in Genomics...want to predict function of 10,000+ genes at a time

- Need to understand environment and regulation for accuracy

- A piecewise solution would be highly useful

- Rate limiting step are the interactions within molecules/membranes...physics behind these interactions is not the main issue

- Sampling problem in "chemical" space...potential of a variety of configurations of the molecule

- True need is for potentials of ligand-target binding and difference between equilibrium separate and docked

- Structure based drug design - use what you can - a future???

- True problem - can you do large scale structure based drug design quickly?

- Manufacturing issues - optimization

- Currently, rate limiting step is the "creation" of molecules; in the future, the rate limiting step is filtering "hits" from "misses"

- Math needs characterization of data, finding patterns in data sets

- $\$ 100-\$ 200,000$ programs justified if there was significant improvement

- Almost all programs at SKB have some computational component

- $\quad$ SKB inclined to bring things in-house

- Consortia rather diffuse and unfocused (approximately $\$ 10,000$ endeavors) 


\section{Richard Feldman and Yuri Sergiev \\ National Institutes of Health August 30, 1996}

- Sergiev is the former head of Moscow's math modeling institute

- In 1990 he initiated the Soviet workstation project...went to the National Academy of Sciences for a "Finding Common Ground" monograph that was sponsored by the Department of Defense...said prohibition against Russians having good computers would change

- Drs. Limm \& Volari were at the forefront of protein modeling research

- He thinks its important that the Soviets get "away from the bomb shop" and into something innocent....but this must be done carefully, symmetrically and irreversibly

- San Dia National Labs is the U.S. makes the clocks for nuclear bombs

- San Dia Livermore is the nuclear bomb shop...will be scaled down

- He has been able to initiate dialog with the Russians in which the two groups are not enemies but friends...the cultural differences are not as great as people in the U.S. believe

- He spent a lot of time "warming up" U.S. companies - DEC, HP to set up operations in the Soviet Union

- Many American companies took tentative steps towards thinking of doing business in Russia, but that was under the premise that there would be a stable economy

- He was able to communicate with scientists across 9 time zones with a $50 \%$ success rate

- Most of the scientists he interacts with came to the U.S. to visit -- some felt they were many years behind in their careers because they didn't have fast computers....Victor Zirkin said his "career is 15 years delayed due to the lack of supercomputers"

- Software developers -- George Michaels, George Mason University in Fairfax, VA (703) 993-1998...extensive experience with Russians scientists that do software development...direct experience with software issues

- By not having computers, the scientists were forced to be more mathematical and intellectual

- When the Russians were first in the U.S., they didn't know how to use the big computers

- The Russians are already well embarked on the process of becoming computational scientists

- Protein folding is the critical problem...solution is the gateway to system design in the 21 st century...critical to generalize protein and system design...if the protein folding problem is solved within 10 years, will be able to design proteins (computing function)

- If you can understand how to fold proteins you will understand how to design proteins

- Infinite sets of computing...this is a good way to get them to focus on protein structure, folding

- Mary Sampsenova in Petersburg --full member of the Internet

- 512 IBM coprocessors in CRAY DoD computer center in Maui

- He is trying to start Protein Folding Inc. - technology transfer from NIH

- Swiss: would synthesize tens of thousands of compounds in a "blind man's war"

- Now the process is that a lead compound is discovered and variants of the lead compound are synthesized

- Merck initiated protein structure study designing drugs based on target structures in 1977

- It costs $\$ 350 \mathrm{~K}$ to do protein structure by NMR or crystallography...takes 3 years from beginning to end in man power

- 4000 compounds in the protein databank at Brookhaven after 40 years...4 million DNA sequences available 
- Number of protein sequences from DNA exceeds those from crystallography and NMR by 4000 vs. 4 million ---there is a huge gap...solution is the gateway to system design in the 21 st century

- If you can understand how to fold proteins you will understand how to design proteins

- Infinite sets of computing...this is a good way to get them to focus on protein structure, folding

- Homology based modeling accounts for $30 \%$ of protein sequences...there is a huge global payoff

- Science Magazine- protein structure production meeting

- Intellectual question: "Why do proteins fold as they do?"

- Answering this question will lead to economic success in the 21 st century

- If you understand how proteins fold, you can design the protein and design better drugs...you can design hundreds of thousands of proteins

- His company took an approach that turned out not to work so well: technology solutions were not adequate; inappropriate management staff; looking for too much money

- Now they are emphasizing things they can really do....they were looking for $\$ 40$ million and now will look for \$10-15 million

- They can now get away with using \$1-2 million computers since the price has gone down

- He doesn't have the desire to use inexperienced Russian labor

- Protein folding is good for people in physics/mathematics

- Other problems: minor technical gains that people in big pharmaceutical companies would be better doing than would the Russians (docking, electrostatics can be more efficiently done by scientists at pharma companies)

- Protein folding is a topological problem - solving it will allows Pcs to solve it in seconds...right now it is a conceptual problem 


\section{Chris Fields \\ Molecular Informatics \\ August 2, 1996}

- As soon as you start looking at non-linear molecules, the issue is can you express this in a linear language. How do you describe a $3 \mathrm{D}$ conformation as a linear string?

- SMILES - linear description language for small molecules

- Can do similarity searches

- If you could describe molecules as a string, you could do all sorts of analyses

- Russians: less experienced in tailoring algorithms to specific architectures...good mathematicians

- They would need someone on the front-end to deal with analysis, problem definition, user interface...Russians could do the algorithm on the back-end

- New models of solvation/optimization

- Basic molecular dynamics calculations are finite element type calculations---let's set up equations and grind

- Whole number of problems that aren't being worked on because they are hard and we don't have a lot of data for checking answers...1 step up from structural biology

- Macromolecular reactions/interaction problems will be solved by classical modeling but also with the input of quantum mechanics

- We are presently using fairly classical methods to solve problems and adding in a little quantum mechanics

- Right now there is no place to do quantum mechanics to see how really big molecules interact

- There are a lot of complicated boundary conditions in space - need to do a lot of exploratory simulations

- Classical approximation: any particular problem would be well-defined up to the point of getting experimental data; would be doing a lot of experimental simulation

- Structural biology- in a complex cell...multiple proteins binding each other and DNA...no can come close to crystallizing them so we don't know what that structure looks like..it would be interesting to predict and be able to see what it really looks like...we really only need a decent solution - don't have to solve the whole thing..prediction has to be within certain constraints

- Doing this type of calculation in a straightforward way is not feasible with any type of existing machine. can only be done through brute force.

- NSF workshop draft report: computational and mathematical challenges in structural biology in February or March. A draft of the report is available. He will end us a copy.

- A lot of people in structural biology are physicists; a lot of people in molecular biology are physicists or at least have a physics background

- "So much of research is serendipity" --- you don't know what's going to work and who will get a lucky break so the more, smarter people the better. It is best to work with people with diverse

- Computational structural biology has never been well funded in the U.S.

- Getting involved in the corporate sector means getting involved with big vendors who can't solve these problems

- The key area is "computational structural biology." This is a hot area: companies have a real need for these answers

- Main issue is learning what they do, but the question is what is fundable?

- Other contacts: Tippel Smith - works on protein structure prediction...in the medical engineering department...does hard computational problems

- Sylvia Spingler - UC Berkeley...mathematical biologist..runs UCSF fellowship program for training grads in this area...knows everybody 


\section{Richard Freisner \\ Columbia University \\ August 20, 1996}

- There are three questions that need to be asked?

- What do people want to do?

- What are the barriers?

- What's preventing calculations from being accurate?

- Visualization is a "service" function...kind of like word processing...no basic science questions...quantitative accuracy is not there...user interfaces work reasonably well

- For simulation, energy functions are not that accurate

- Speed is very important

- Getting good enough statistics so you can measure the binding energy is important

- Goal is to be able to take 500 molecules and estimate the binding energy

- Computational accuracy and a sampling size that is broad enough to be statistically significant is important and will save money

- Family structure and some input data is needed

- The only thing that simulation does at this point it to rule out things that are "really bad"

- Both the scientific (function) and algorithm (statistically significant) problems are at the heart of the issues

- If accuracy is achieved, there is an opportunity; question is what level of proof is required?

- There has been some backlash on "rational" drug design... started in the early 80 's..tremendous hype and big investments made by the large pharma companies

- Combinatorial chemistry is intuitive, thus the big executives will be willing to invest a lot of money

- Demonstration that you could do accurate calculations is the validation... started in the early 80's.tremendous hype and big investments made by the large pharma companies

- Combinatorial chemistry is intuitive, thus the big executives will be willing to invest a lot of money

- Demonstration that you could do accurate calculations is the validation

- MSI is trying to go public

- 40 people working on this at Columbia...they have their own software program

- Making a breakthrough will depend on skills, having experience in the field and on what people have tried before

- Tripos is more focused on combinatorial chemistry, not competitive with MSI in area of optimization....MSI has a quasi-monopoly

- Low effort in commercial area on improving programs, more time spent by academics (Columbia, UCSF, Scripps)

- The key is to have a breakthrough in basic science

- Two issues: Where can we take the existing technology? and If the existing technology is not good enough, what are the hard core problems that need to be addressed?

- Time scale is probably $2-5$ years

- Purchasing decisions usually made by the top executives...programs cost anywhere from $\$ 100$ to $\$ 100,000+\ldots$ MSI sells total packages that cost $\$ 300,000-\$ 400,000$

- Purchasing decision time is usually 6 months to 1 year

- Question as to whether an improved application would make money depends on whether or not it is a compelling application...you could probably generate $\$ 200,000$ and maybe even \$1 million, but it's just depends on the program

- If it really works, you will be able to get venture capital backing 
- A lot also depends on the competition and seeing who will come up with something

- Drug companies have a monopoly on testing..biotech companies are trying to have unique technology to partner with the big pharma companies

- If you make molecules that are more specific there is more of a chance that they will turn into a drug because you can use a lower dose

- All of the current programs are all different yet are all different in the wrong ways...no two potential functions are similar

- Proving structural-based drug design will be a big factor in whether or not combinatorial chemistry or structure based drug design is a bottleneck

- Qualitative visualization products is a highly competitive environment

- PC proven to be a as accurate as SGI Workstation

- Question as to whether an improved application would make money depends on whether or not it is a compelling application...you could probably generate $\$ 200,000$ and maybe even $\$ 1$ million, but it's just depends on the program

- Proving structural-based drug design will be a big factor in whether or not combinatorial chemistry or structure based drug design is a bottleneck

- Qualitative visualization products is a highly competitive environment (cache, hyperchem)

- Making the programs easier to use and bringing it down to the expert user is a different issue...the question needs to be answered "does it get to the right answer?"...could generate tens of millions of dollars

- Ideal situation would be to make the programs more accurate and take it down to the desktop

- These scenarios constitute two different investment paths

- In the end, it's a marketing question...matter of talking to organic chemists...very sales and marketing driven

- Bring it down to the non-expert

- PC proven to be a as accurate as SGI Workstation...proved in the Journal of Computational Chemistry (Monte Carlo) by Bill Jorgenson

- Believes that bioinformatics is "real" because people want to find targets and figuring out the structure of a gene goes a long way in finding targets

- Scientific Barriers: how are potential functions developed?...how do you develop potential function that works in a condensed phase?...systematic protocol for guaranteeing accuracy...have a lot of degrees of freedom and try to get sampling energy

- Potential energy calculations are areas of improvement (condensed phase (liquid, solid))--- gas worked out...degrees of freedom (statistical significance)

- Others to talk to: Kollman, Karplus, Bill Jorgenson (Yale) 


\section{Angel Garcia \\ Los Alamos \\ August 2, 1996}

- Theoretical Division at Los Alamos includes Cell Biology, Informatics, Structural Biology

- Theory is now separate from the weapons division...14 groups, some groups have sections

- Currently looking at a system that degrades pollutants...looking at CFC's and how reactions occur

- Looking at proteins and trying to make them better with experimental groups...look at protein DNA complexes...look at modeling for structures related to mental deficiencies

- Russians know very little about biology/chemistry...they are doing fluids, which is what weapons people do...he would characterize them as physicists with very good numerical ability

- Russians are the "physicists of the 40's"...That's a compliment. Because they don't have the computers, they are very good analytically

- When the Russians came to visit for a week he thought they were excellent physicists who were able to understand problems without a lot of explanation

- The question is what value can they bring to biomolecular modeling?

- Combinatorial chemists know a lot about quantum mechanics but not thermodynamics mechanics, so their work in this area is often sloppy and inaccurate

- Two parts in science: postulating the problem, solving the problem. They cannot do the latter but they can do the former.

- Electrostatics problem -- physicists will solve much better than biologists

- Biologists could postulate the problem and the Russians could solve it

- US has people that could solve the problems, but the issue is cost..it costs $\$ 200,000 /$ year for U.S. scientist - could get 4-5 Russians for the same cost

- They look at problems much differently...by knowing how they do electrostatics/fluid dynamics, we will know their weapons

- Feels that the Russians will be somewhat protective of teaching others their skills.

- We gave them the software to "get their hands" wet; he gave them problems he had solved...want to be funded by the State Department but the funding hasn't come through yet...needed funding to buy computers.

- They've done most work on PCs, Fortran...would only take them a couple of months to learn $\mathrm{C}++$, but to learn subtleties of the language will take much longer

- Program language not a barrier for them

- Several opportunities to write simpler programs for the PC: optimization, minimization, and docking programs

- Software simulation-- he can't see faster ways than we're doing it

- Simulations - for a problem involving proteins that decompose pollutants, it takes about 1 month to run; would take 4-5 years on a PC; we could improve the program and it would run faster.

- They are also very good at error analysis: define the error you want and then do a calculation based on the error range.

- Another problem is continuum approximation -- example is trying to model water

- Solvation -- they are good at developing algorithms...the models wouldn't change but the way of solving the problem would change

- Some possibilities: new optimization models; molecular similarity; modeling reactivity of combinatorial mixtures, electrostatic potential.

- Two ways of solving the problem of modeling the boundaries around a molecule: 1) finite differences - it takes about a half hour to run but there are limits in accuracy 
because you cannot grid space as fine as you want; 2) finite elements - it takes about a day to run a program but it is very accurate. These kind of programs are often used in ligand binding experiments. Ideally would want a program that is as fast as finite differences but as accurate as finite elements.

- Physicists do finite element approach all the time because its the best way for testing...possibility that the Russians could either do it faster or at the same time with more accuracy

- Optimization: fitting where you have function and you want to find a set of values to fit the curve...docking is an optimization problem...Russians are very good at doing this

- Example of optimization: getting the thermodynamics of a system - what's the ideal thermodynamic state.

- Simulation is mostly an algorithm exercise.

- XI - Princeton, NJ...developing codes and algorithms for fluid dynamics

- Stephen Orsgag..consulting and software firm

- Russians could work in other areas besides biomolecules

- Molecular simulation - understand algorithm analysis and could make better approximations but Russians probably couldn't make a magnitude of difference

- Molecular similarity - mathematical problem; need to find algorithm between two functions

- Electrostatics - continuum models

- Simulation - particle simulation but not restricted modeling... you care more about shapes

- Simulation really falls into two categories: particle simulation or distinct modeling where you care about shapes; and continuum modeling where you are dealing with fluids and are concerned with solvation, electrostatics, and fundamental physics

- If the problem is well-defined, the Russians could solve it with little interaction; but in order to dissect the problem, it needs to have been attempted or solved by someone in a not so efficient way

- Thought about trying to use the Russians in the educational market

- We have no real proof of what they can do...no real hard evidence

- Many biologists think that physicists solve problems for which there is none...these are applied physicists, not pure physicists

- Maybe having them here for a year to see what they can do would be a good option...pay them a consulting fee 


\section{Jonathon Greer \\ Abbott Labs \\ August 20, 1996}

- Limitation is in science, not programming

- Goal is 3D structure of target and ligand

- Free energy of binding cannot be done today accurately...will take a major breakthrough in science

- BioSyn/MSI consortium has been working for more than ten years

- "Multiple-minimum" problem --so many blips you can't tell which is the true minimum...this is a major problem and if solved could revolutionize the drug discovery process

- For a given function you want to get the minimum...this is a math problem

- Evaluating a function for a realistic description is not a math problem

- Combinatorial chemistry is generating diverse libraries

- MSI, Tripos, etc. focus on "user-friendliness" and "bangs and whistles"...not really a major limitation...BioSyn/MSI consortium has been working for more than ten years

- MSI, Tripos, etc. focus on "user-friendliness" and "bangs and whistles"...not really a major limitation

- Giving a program to a novice, you need to have sound science...need the "expert" user to tell when the answer is correct and when it isn't...bringing programs down to the novice level could be dangerous because a novice thinks the wrong answers are right

- Novice users might use programs only once a month --where intuitive, user-friendly stuff would be very helpful

- They are stretched thin in his department -- must prove "we" really need it

- Less funds available -- rational based drug design is more "mature" than combi chemistry, etc.

- Current programs are merely incremental increases in previous versions 


\section{Dr. Barry Honig \\ Columbia University \\ August 13, 1996}

- Believes that the products for biomolecular modeling are virtually the same

- Does not think that anyone has done an objective comparison and that the nuances between the various programs are not worth mentioning

- Different ways of designing drugs: "classical/traditional" approach and "structurebased"

- In the classical or traditional approach, the scientist learns something about a molecule that binds to a protein even though he might not know what the protein is

- Structure-based design is when the scientist knows what the protein looks like and tries to design the drug so that it fits into the protein.... "he has a picture of the lock and is now has more flexibility in designing the key"

- Visualization programs used for designing the drug when you know what the protein looks like...instead of using a mathematical equation you can use visualization or graphics to get a pictorial description of the molecule

- Products for visualization include "Insight" and "Quanta" which are both sold by MSI and "Sybyl" which is sold by Tripos

- The classical or traditional approach has still been dominant...scientists are reluctant to go towards structure based design because of the clash between chemists who don't want to be bothered by computers

- Combinatorial chemistry: goes away from using structure to designing the molecules...you become "dumb" again...you are simultaneously designing the locks and keys

- In structure based design, the scientist was limited by time....took a lot of time in a lab to design different molecules that would bind to a specific protein.

- In combinatorial chemistry, the synthesis methods are automated...hundreds of thousands of molecules are made simultaneously, making the "hit" rate higher and requiring less accuracy

- The problem with the current programs is that they are not an accurate predictor of how molecule fragments stick together

- MSI has a consortium of large pharmaceutical companies that is looking at ways to improve MSI's current software by using more clever algorithms or by using faster computers...however, people are not convinced that it will be that useful because of the trend towards combinatorial chemistry

- Need combination of mathematicians/chemists for combinatorial chemistry

- Biologists are more interested in bioinformatics...lots of work being done in this area right now especially with gene sequencing

- Purchasing decisions currently made by computational chemists and those doing structure-based drug design...they make the decisions at the levels of their own group

- Believes we would get a lukewarm response to the value of Amber/Charm...companies pay maintenance fees on these products...better response for $3 \mathrm{D}$ database searching programs

- Visualization tools used the most often, followed by similarity ("used by the large drug companies all the time") and then simulation

- Growth lies in the area of 3D database searching and the connection between chemistry and biology

- Of the 100,000 proteins, we know the structure of about 3000

- Structure-based drug design has leveled off even if product improvements are made

- Believes bioinformatics also a wave of the future...SmithKline just hired 60 people to do analysis in gene sequencing...it "may be hype" but he thinks not 
- Starting a biology company today is viable, but you couldn't start a chemistry company with solely chemistry and computers

- No real products in area of 3D database searches 


\section{Richard Judson \\ San Dia Livermore \\ August 20, 1996}

- QSAR is becoming big...might add it as a stand alone category but it also incorporates some similarity

- Quantum chemistry stands by itself...accurate energy of binding/develop force fields of energy

- Three steps in drug design: somebody has created a protein structure and wants to design molecules that will bind to it

- First they visualize the molecules graphically (visualization)

- Then they pick out properties of the molecules that bind to it and simulate it

- Then they do similarity to find other molecules that will fit to it (visually or QSAR)

- Simulation

- Very difficult calculations to do

- A lot of quantitative information, but the error bars are very large

- Pharmaceutical companies shy away from simulation because the computer problems take so long

- Believes companies would love to do good simulation, but the calculations need to be more accurate, especially the docking calculations; need algorithms to calculate the forces between small molecules and proteins more accurately

- Simultaneously you need to make the binding more accurate

- Solvations - 75-90\% of binding solvation...the more sophisticated they are, the more expensive...should bring accuracy up and bring the computational effort down

- Key hot area is to get around the problem of protein structure prediction -- means taking the protein sequence to structure the protein

- Academics in Europe spending a lot of time in this area

- Lots of unknowns left...\$1 billion per protein to get $\mathrm{x}$-ray crystallography structure

- Threading methods - use force fields and confirmational searching techniques

- This is a growing field, and not yet commercialized...in two years it will generate a lot of dollars

- Current methods can get to $50-80 \%$ of structure

- Could take current programs in this area and make them more robust....they currently tend to be hard to use because they are academic programs

- Molecular Applications Group - company doing academic protein modeling code (415) 846-3570...their venture capital companies are Medicus (Fred Dosler - 415-8547100 and Morganther (415) 233-7600

- "Will win Nobel Prize if solve protein structure"

- Currently, if they have $50 \%$ of the sequence, they could predict structure $<20 \%$ of the structure, could not predict structure $20-50 \%$ is a gray area

- Current programs can save you a big chunk of time, but huge classes of proteins are left out

- Everyone is working toward the same goal for protein structure prediction

- People work in isolation - have suite of codes that work together...confirmation searching methods, but different people working on different aspects

- Common interfaces between solvation methods...Java-like format

- Hybrid method: no one has put effort into making it work: a lot of groups around the world making a standard

- MSI tried this with Cerius 2 but it was a data version that didn't have good implementation

- MSITripos: at first they thought they could do it all but then they realized they couldn't make money that way...(develop and sell code) 
- MSI bought out BioSyn...the methods development people got fired and the people who could upgrade academic codes stuck around...this makes sense from a business standpoint

- Many academics creating small companies to market a particular code...being driven by ease of building a nice graphical user-interface

- Gausien Inc.--premiers quantum chemistry code...remained as an academic company

- Bill Goddard - Cal Tech...started BioSyn...involved with wave function

- No one makes a living doing this

- Cost: academic group $\$ 1000$; commercial company $\$ 10,000$

- Academics have specialized programs on what MSI/Tripos does

- Two or three tried to be the next MSI - only Daylight has lasted more than 2 or 3 years

- Most of these academic programs are simulation code/no one can answer these questions in a definitive manner

- Most of the people in methods development have a $\mathrm{PhD}$ in chemistry...sometimes have a physics or computer science $\mathrm{PhD}$

- Chemistry people have atrocious coding skills and are not using modern software techniques

- Physics/computer science are more hackers

- Some pharma companies hire computer scientists...fancy databases/information databases

- Never seen ads for people for degrees in math/physics

- $\mathrm{PhD}$ in math - theoretical/academic....practical -.- computer science

- Physics -- no reason he shouldn't be in the same field as computer scientists or mathematicians

- "Organic chemists are 'demi-gods' in pharmaceutical companies...they like people with chemistry backgrounds

- Him in grad school

- Computational group: two groups: quantum mechanics/and molecular mechanics...pharmaceutical co.'s didn't solve problems then no jobs for these people

- People got to the point where they could do nice calculations on big proteins

- Pharma companies are looking for people who are informatists - similarity...chemical intuity to say what the next combinatorial library should be

- Structure people couldn't keep up with the simulation people

- How do you make experimental process even faster?

- Lots of companies getting into search genome database - what protein do you go after for some gene; pure information process

- Elegant simulations not needed for combinatorial chemistry

- Combinatorial chemistry might be a fad: only certain classes of molecules can be made with combinatorial chemistry (peptides, peptoids, DNA - but body eats these up)

- Drugs that work are complex molecules that you can't make combinatorially...delivery problem may be insurmountable...large companies have big modeling groups because of this...simulations at the end not the beginning

- Combinatorial chemistry - 10 lead compounds.... "what is toxicity?"; what is "bioavailability"?

- People are developing metabolic pathways which will tell you the fragments and will allow you to see if they are toxic

- Could also take fragments and do similarity comparison

- Toxicity is in its infancy -- some think this is so complex that you can't see signals in predictions

- EPA has funded research in toxicity...could have a huge payoff

- Bioavailability - solubility issues...(pill in gut - needs to be in greasy vs. water part of molecule)...active methods of transport in and out of cell 
- People are starting to get information about molecule and what info you need about pumps...robust methods for predicting bioavailability

- Protein structure prediction is a big deal right now....tools have a chance of being made robust and powerful...groups currently looking at this haven't gotten the "money lust" and could be exploited

- Currently many more ideas than number of people to work on it

- Take genome database and predict shape of every single protein - $\$ 5-10 \mathrm{~K} /$ structure

- Russians should operate as a service because once you sell code to a company they don't need you anymore, but if you sell a service there are several molecules (PKA/synthesize number of molecules - consulting)

- Computers are so cheap today that these companies have a chance

- Tiger - started as a service and then they started selling information

- Problem with selling information is that pharma companies won't disclose proprietary information about a molecule's structure -- won't trust you enough to look at the data

- Programs on the Net (sequence analysis)..you email protein sequence and they email you the structure back...confidentiality is an issues...there has been talk about using Java to encrypt data going in so that it is really safe...may be a way to get around proprietary issues

- No one will make money trying to compete with MSI in simulation...only if "breakthrough"...no market for trying to do something incrementally better than MSI

- MSI and BioSyn merged because they were both losing money

- Tripos is currently losing money

- He thinks protein structure problem is the hottest area...but the venture capital community responded by saying that the "technology is too immature"...2 years from now it may be really hot

- Quantum chemistry is saturated

- Genome informatics - competition is national databases that give away information for free

- Individual can make a living working for one of these companies, but it is not really an opportunity to start a business with a lot of money

- Computer is an analytical tool...market for analytical tools?...tools toward end of process...real dollars are in selling something to company...real cost is clinical trials/not much money is spent on R\&D...clinical trials won't be affected with computers

- Richard Feldman - NIH - started company for protein structure...(301) 496-1100

- MSI is decreasing revenues from methods development...pulling off software from academics

- Academics - small companies writing code

- GUI - Molecular Applications Group - building from programs

- Gaussian

- Bill Goddard at Cal Tech (BioSyn founder) started company ....re: quantum chemistry

- Money from small companies is added salary, not "a living"

- $\$ 1000-10,000$ license fees

- Daylight is the only company that survived "trying to be the next MSI"

- "One" program can't "solve it all"

- Methods development (computational chemists) - chemists, comp. scientists, chemistry and physics background - have bad coding skills

- Pharma companies hiring computer scientists, not looking for math /physics who could learn chemistry

- Management are organic chemists - don't like the learning curve of physics

- Informaticists - combinatorial chemistry design, target searching in database...drugs on market are large and complex (peptides, peptoids, DNA, organic)...structuralists not as "quick" in design 
- toxicity (toxics from metabolism (degradation)/bioavailability - already done in some respects/understand pumps, pka

- QSAR - similarity measure of toxins, receptors 


\section{Dr. Tack Kuntz \\ UCSF \\ August 20, 1996}

- Medical Applications - P. Chem; Biophysics; Pharm. Chemistry

- Software development - graphics, molecular dynamics (Kollman), stats, polymer chemistry

- 100 people doing theory

- For the last 15 years he's been a champion of "structure-based drug design"...gives more info than biological activity

- HIV protease inhibitors all developed using SBDD (papers proven)

- Generic areas not yet - if enzymes are targets, good chance

- Tools for this community

- Corporate/commercial databases in past use (up to 2 years ago)

- Available chemistry libraries by MDL Information Systems

- Last 2 years shift to virtual libraries $10^{20-30}$ molecules

- Graph theories - constantly at frontier of science

- Advice:

- Short on chemists - integrate strong synthetic group

- Clever computer algorithm - can produce great compounds but not usable

- MP complete problems, partial solutions are possible/okay

- Chemical interface

- Hook up with pharmaceutical companies, biotech groups (ArQule, Pharmacopiea, Affymetrix, Amgen (slowly), Genentech, Chiron)

- Focused work-science, application learning curve not possible in 6 months - year

- Eugene Shackovitz - Harvard

- Raw computing power not enough benefit to offset budget constraints

- Takes 3-5 years to write or distribute software

- \$50-100K "academic" contracts possible

- Need bioinformatics - "science" "solved" building off existing problem

- Computation chemical theory (little bit computing power) coupled with chemical theory

- 25 years into science, at least 10 years until 10,000 workstation tech in front of chemists at pharma chemists (bringing down to level of "novice")

- Tapping into information; graphics \& modeling, internet, intranet

- Tripos, MSI local

- Downstream parts of drug discovery

- Toxicology - clinical trials losses

- Genome project information - sequence alignment, functionality

- Modeling a cell - statistically significant information not there

- Molecular Design Institute at UCSF

- mcclosk@cgl.ucsf.edu 


\section{George Lauri \\ Pharmacopiea \\ September 4, 1996}

- Software design entails automation of existing software

- Companies are either buying products out there and putting them into use or not buying them

- Opportunities:

- Mathematical model design...design of experiments

- Property spaces abstractly and physical reality correlation

- Quantum mechanical models

- Development of key technologies

- There is a lack of sophistication in computer science code

- Little interaction between programs

- Commercial software companies are "dumbing down"

- Interfaces are database oriented - central repository of data

- Organization of large software systems

- Physics and math roadblock

- Robust, efficiency, require lots of baby sitting

- Poor quality, but designable

- Work around assumption of one problem/application at a time

- Most consortiums are a waste of time - pharma companies "not willing to spill their guts"

- "Highly focused groups" -- smaller consortiums...could suggest ideas and analyze data

- Statistical analysis of data to trim combinatorial chemistry hits...he doesn't know what new technologies look like

- Technologies good enough to use as an idea generator only

- Need to find accurate way to characterize structure/function and predict binding

- In future, need number of tests to build accurate models to guess data...need to design experiments that would be useful and how to analyze that information

- Solvation - physics is the key problem

- Metabolism - complex just for the sake of complexity

- Time factor - computer speed curve not growing as fast as experiments curve (factor of 10)

- Combichem wouldn't slow down in the near future

- Shave off a couple of years (traditional cycle is 12 years)

- Combi chem library is 6 months off - 12 years

- Toxicology models/metabolism - really good for known areas

- What experiments already proven; still need validation

- Toxicology models - little physics and math/need more data crunching

- Predicting whether clinical trials will fail -- essentially only changes the ranking

- Does nothing

- Does bad and nothing

- Does good and bad

- People would pay for slightly better than incremental improvements

- Mathematical - formulation question in mathematically understandable terms - problem

- "Think tank" option - pose questions...\$1000-\$2000 day current figure per person

- More immediate needs:

- Protein folding would be a very good thing

- People have become jaded

- Wouldn't necessarily be revolutionary

- There has been a lot of work done, but experiments with molecules is easier

- Computers good for analyzing data, but not so good in large quantities 


\section{Robert MacDowell \\ Senior Scientist \\ Genentech \\ July 30, 1996}

\section{Simulation}

- Simulation category is fundamental physics, including quantum mechanics, empirical, free energy perturbation

- Simulation doesn't really represent what molecular modelers in pharmaceutical companies do

- Simulation is useful, but predictability is small. You need to take short-cuts and you can't describe entropy. "You don't know how to energetically describe water and you don't know how to describe entropy."

- Low end simulations used daily in building models. Used to look at properties of molecules

- Used to make hypotheses

- Quantum Mechanics

- Gaussian, developed at Carnegie Mellon, is "the workhorse" of quantum mechanical programs

- Semi-Empirical Methods

- QCPE - IU Bloomington acts as a clearinghouse for either self-contained programs or little routines; typical grad student coding and available for free

- Empirical Force Field (for large molecule proteins). All of these programs do the same thing. You would just buy one.

- Amber- written by Kollman at UCSF; distributed through Oxford Molecular, which like QCPE is a clearing house but for more complicated codes

- Charm - written at Harvard; commercialized through MSI

- Gromos-- University of Groningen; "granddaddy of molecular programming"; not as much exposure in U.S.

- Discover -- MSI proprietary program

- Explor -- outgrowth of Charm

- Above programs simulate proteins without using a totally empirical approach/using classical force field; computational intensive; permeations have to be small so cannot really use them for large

- Small molecule programs-- MMZ; Macromodel

- Market is saturated with programs

- There is definitely a need for better products. In many cases it is based on a better understanding of physics, e.g., a better understanding of solvation.

- the faster the algorithm, the better

- can't simulate long enough to reproduce biology; can simulate in nanoseconds, but changes occur in microseconds

- theory in crude level -- no experimental database. You make assumptions based on an additive sum methodology; but rarely do phenomena translate in an additive basis.

- A lot of the coding is done by graduate students; it works but it is often not the most efficient code writing 
- More efficient code the better but chips are getting so fast that they can override the inefficiencies in coding

- Biggest Achilles heal is the theory. The bigger the theoretical model, the more likely you will overcome inefficiencies. These models are extremely complex and unwieldy

- Simulations used by theoreticians occasionally in an industrial setting as hypothesis generators

- Most benefit will be in providing models that embody the essential core functions. These will always be used and occupy the most time in developing.

- Discover-- much easier to use and contains self-contained language

- Hard core simulations- Gromos, Amber, Charm

- General modeling - Discover, Charm

- NMR - Gromo/Chamber

- It's a "well-covered playing field"

- There is a growing interest in 3D docking algorithms -- this will become more important in the future; it is big in combinatorial chemistry

\section{Visualization \& Analysis}

- Graphics code is hassle

- Silicon Graphics - They have set standard for 3D graphics

- Graphics code is unique to the box (not so with other codes)

- The trend is to couple visualization and simulation ...real valued added...Tripos/MSI getting into this. Can see it and do a simple interactive simulation - simulating energetics and interactions

- Can modify amino acid while sitting in front of screen

- Emulating geometry

- Have to analyze huge trajectories of data

\section{D Database Searching (Molecular Similarity)}

- "Exploding right now"

- Biggest opportunity for unique algorithm development

- Old programs converted molecules into 2D graphs. This has been the primary way pharma companies keep track of compounds/can look to see which other molecules have core molecules

- Need to develop algorithms where you can look at molecules in 3D space in real time. Want to be able to search over 3D attributes, angles. A lot of molecules cannot be looked at low energy conformations.

- Tripos- "on the fly" searching of molecules...coupling database with simulation

- Exploring trend: using combinatorial chemistry to explore structure vs. blind screen

- It is now possible to teach computers to assemble molecules. Instead of "matching" a compound's known properties against an existing library, what you would like to do is create libraries based on predetermined properties. Your library then becomes much more selective and you end up generating libraries of molecules on the fly.

- You want to go beyond static molecular models

- The goal when using libraries in drug discovery is "to optimize diversity and minimize redundancy." The biggest fear in dealing with a library is having a lot of molecules that are similar. You want to be able to create a library that optimizes the diversity of properties that you are trying to evaluate. That way you can be much more efficient in getting to you answer. 
- Combinatorial chemistry will merge with computational chemistry in the next few years

- Pharma companies investing in modeling strategies coupled with library approaches

- The problem is that we don't have enough understanding of the energetics of binding for a computer to weed out what we don't want to see. To compensate, you end up lowering your threshold and you end up working with too many conformations.

- Room for creative/nonparametric statistics

- Satellite pattern recognition is an example of the abstract pattern recognition that is needed in 3D database searching -- you take profusion data that no human being could sit through

- Blaney's group at Chiron developed combinatorial library that will optimize variability/minimize redundancy

- You want to couple conformational model building with abstract statistical approach -library design and reforming initial library structure around hypothesis -- potentially lucrative business and represents the biggest growth opportunity

- If libraries are too big, screening is a problem

- Tripos -- aggressively pursing this area and is the leader, mostly for small molecules.

- MSI -- starting to pursue it; emphasis is macromolecules

- Both of these companies are wedded into making monolithic product lines where everything is integrated

- These companies need to pursue this new modeling approach for growth because commercial base is saturated

- No one should spend time improving the current graphics code. Silicon Graphics has a simple way to visualize graphics. If you combine this with high end algorithms you can put together a good modeling package.

- It is no longer necessary for 1 group to write "soups to nuts" programs. It is much better to take a tool kit approach that allows users to do their own modifications. Need is for clear cut data structure that can be plugged in as a molecule.

- Russians should talk to MSITripos...don't have algorithmic programming sophistication. The problem is that with MSI/Tripos:

- They know chemistry but they don't have good programs - clunky

- Monolithic package

- Very costly; bundle everything; steep licensing fees.

- Small companies can't afford to buy it

- Strict licensing rules

- Want to take soup to nuts approach but won't make changes to product

- Oxford Molecular Group is another good company for them to talk to...possibly as a distributor

- Smaller, don't have high end user support

- Not financially invested in software because they only distribute it

- "Sleaze" factor less because associated with university

- Have people that understand the biology

- Philosophy is that the users provide the sophistication and they provide the tools to develop

- Collaborate with academic groups like Kollman/Wilford van Gunsteren...would give them instant credibility if they were associated with an academic field

- When he (MacDowell) looks for product, he looks for:

- Ability to modify

- Flexibility of use

- Efficiency

- Will invest time to learn 
- Aries Pharmaceuticals have invested a lot in having sophisticated end users

- Good to couple with "power users" with groups like Oxford or Charlie Brooks at Scripps (wrote part of Charm)

- Academic groups: Karplus, Kollman, van Gunsteren, Goningen (Netherlands)...not many good groups doing small molecules

- Garland Marshall --founder of Tripos...he's at Washington University in St. Louis..."can separate weak from chaff" ..invented a large part of field

- Tack Kuntz at UCSF: DOC program -- will go through enzyme site and figure out molecules that might bind to it.

- Other contacts: Aries Pharmaceutical; Bob Stroud at UCSF, a crystallographer

- Agouron Pharmaceuticals

- DuPont Merck - did a lot of 3D database searching successfully in the development of their HIV product.

- Paul Bartlett - Berkley; classical organic chemist- practitioner

- Clark Still - Columbia; developed conformational searching algorithms

- Person in his type of group or IS group would do purchasing for database search...a lot of IS groups research information and handle databases

- Bioinformatics, which is protein/DNA sequence analysis...represents hot growth area

- Bill Wood...sequence analysis at Genentech

Costs:

- Amber - \$12-15K; one time purchase..new version every 3-4 years

- Charm/Discover - \$100-150K; $15 \%$ maintenance charge per year

- Axel Brunger wrote Explor--NMR structure refinement...no longer by old fashion interactive way...almost every crystal structure refined by Explor

- Commercial companies are incorporating/refining methods out of academia

- Commercial companies made killing with NMR and crystallography

- Explor - huge customer base/100's of protein crystallography labs

- Amber/Charm - can get \# of installed bases from company

- Tripos - has been around the longest...their software is still unique to small molecules

- Every protein academic lab has Amber or Charm

- $\$ 60-100 \mathrm{~K}$ for small installation of 3D database searching

- Tool kit approach...C++ language...versatile, someone who will know how to assemble the tools

- Similarity - 3D database will be combined

- He wants to get something going with 3D database searching

- Hooking up with an academic lab will get instant visibility

- Scripps - creative --- "gearhead".. Charlie Brooks/Dave Case

- MSI and Tripos...worthwhile to look at them...will do everything they can to make money

- MDL - Molecular Design Limited in San Lendro; 2-D right now; looking to partnership with Tripos

- Talking to biotech companies would also be good...industry doesn't have quite as many "sharks"

- Basic physics behind all of this is simple because that's what you can do on a computer 
- Material Science- big financial opportunity in the U.S.

- Molecular Solutions: talk to Mary Ambros; see their web site 


\section{Gerald Maggiora \\ Upjohn \\ August 20, 1996}

- Would take a broader view and divide up modeling into three categories:

- Chemical Informatics - relational database with chemicals/structural, property information/also biological data...high throughput screening data...represents the most important area in applying computers to drug discovery...relational databases: structure, properties, preclinical bio data

- Molecular modeling (visualization/simulation/similarity)......

- Bioinformatics...can't do this without computers

- Upjohn is doing database searching for novel "scaffolds" and to build "ideal" therapeutics...combinatorial chemistry is "targeted screening"

- Simulation needs people who know programs and who use them frequently...really a qualitative tool (lots of technical hurdles)

- Similarity concept is very intuitive, even though program is sophisticated...chemists have a lot of pressure to produce molecules

- Chemists ask simple questions; simulation is too long (time), too technical...theory and methodology not to the point that they are accurate enough to replace measurements

- All tools used to design drugs, but the degree of simulation is low

- Want computational instruments that have the accuracy of "wet lab" experiments, the simplicity of "desktop" software

- Want "rank order" binding to target of potential molecules

- Environmental conditions/variables too complex to make simulation useful -- right now not accurate enough

- Speed must be faster than "wet lab" experiments

- Biggest inroads can be made in data visualization (ability to screen out misses), not molecule visualizations

- 200,000 Upjohn compounds

- No tools out there for data visualization

- Modeling needs lots of structural information to be accurate

- Data visualization also important in drug delivery, manufacturing, clinical development, materials science (very little simulation, similarity done right now)

- Now less proprietary staff due to research demands

- Similarity is important..simulation is more specialized...simulation programs are very sophisticated and complex and they are not "desktop" programs

- Believes the future lies in each of these areas and the programs need to be interactive

- "Don't manage thousands of pieces of data without a computer"

- Vertex and Agouron - doing structure-based drug design...first need well-known receptors

- If you have a well-defined receptor protein, you can design drugs that have binding property --- it might not make it through the other channels but it will definitely have binding potency

- Databases/3D database searching-- trying to emulate how scientists think

- Have used database searching to do novel templates

- Combinatorial chemistry is the "dumb" or "irrational" approach versus the rational approach...Upjohn uses it more from a targeted perspective "semi-dumb"

- There is not going to be any methodology that in all cases satisfies your needs -- in most cases you don't have structurally well-defined targets

- Have to integrate all data and need design/modeling/bioinformatics tools

- Graphics underlies everything...similarity has the greatest impact and is used by everyone and is the most used tool (general concept)...simulation is the most specialized 
- 200-300 people doing similarity at Upjohn ...much broader usage than simulation...Have to integrate all data and need design/modeling/bioinformatics tools

- Simulation: sophistication of program/most are not desktop programs...have tons of functionality

- Detailed simulation currently in the hands of specialists

- Limitations of simulations: reliability of potential energy functions/treatment of solvations

- Graphics/visualization is inherently more intuitive

- People can use the tools, but with binding there are a lot of technical demands

- Chemists have a lot of pressure to produce molecules..will not spend time to do it unless it's simple and not time consuming

- Value: what is the ease of use? ....what's the reliability? ...they have to be better than they are now

- What they would like to have:

- Computational instruments that can be used in an easy way

- Improved calculations of solubility of proteins and their binding to proteins...Detailed simulation currently in the hands of specialists

- Limitations of simulations: reliability of potential energy functions/treatment of solvations

- Graphics/visualization is inherently more intuitive

- People can use the tools, but with binding there are a lot of technical demands

- Chemists have a lot of pressure to produce molecules..will not spend time to do it unless it's simple and not time consuming

- Value: what is the ease of use? .... what's the reliability? ...they have to be better than they are now

- What they would like to have:

- Computational instruments that can be used in an easy way

- Improved calculations of solubility of proteins and their binding to proteins

- User interface without a lot of time invested

- Reliable estimates of characteristics of molecules/proteins

- Improved electrostatics

- Speed important in coherent design process...... "better if you can do it faster because you can ask more questions"

- Techniques of doing these large calculations to estimate are laborious...big calculations that take hours

- If you had ease of use/reliability/speed....it would be extremely useful if you had these things

- Data visualization key to future...complexity of the data is increasing...will be looking at 1 million molecules instead of 200,000 molecules

- Can't put in all structural information and input 10,000 molecules at once

- If you have bright people, analytical skills will be useful

- Visualizing/synthesizing huge trajectories of data will be the future...he calls it a "big tidal wave"...things look calm now

- This is also an area where things will definitely spill over from research to development

- Development currently uses little visualization and simulation, but have physical-like chemistry problems

- People in development haven't gravitated towards these programs

- In the past, Upjohn has developed their own programs, but now they are doing more off the shelf type of stuff

- 18 people in his modeling group

- Just merged with Pharmacy...colleagues in Europe and Sweden use off the shelf type programs, he wants to have an integrated environment

- But, off the shelf programs sometimes won't answer the questions they want to ask...vendor sometimes won't let them make changes 
- Commercial companies aim at expert or specialist user desktop system

- Current products are more specialist oriented

- Commercial companies really aren't focusing on what to do with the large masses of data

- Have gotten good usage of their own software programs at Upjohn

- Molecular Applications Group: bioinformatics (Palo Alto, CA)

- MDL Information Systems: chemoinformatics (San Leandro, CA)

- Technology is getting more sophisticated...ultra high throughput screening 


\section{Brian Masek}

Zeneca

August 22, 1996

- Zeneca does visualization, simulation and similarity

- "Classical" drug design is a mature field, but it doesn't mean there couldn't be breakthroughs

- Combinatorial chemistry generates enthusiasm and excitement

- Information management - screening hundreds of thousands of compounds

- Can you recognize from these data patterns neuronets...other sophisticated analysis

- Two potential areas:

- Protein ligand docking - not reliable predictors of binding affinities

- Multiple-minimum problem part of docking...take sequence and predict fold and design ligands that predict reliably---can do some of these things some of the time

- Combinatorial chemistry - diversity design: compare diversity of one set of compounds to another set of compounds

- They have combination of products: Amber, Tripos, MSI, in-house molecular shape

- The whole process works together...most critical: how to generate leads...once they have leads they have established the target... what is the stage at which they think they understand biology?

- How do they find leads?...they have various computational tools and combinatorial chemistry tools...protein ligand docking (in-house)

- A lot of the tools come out of the big pharma companies

- They are "generating their own innovation"

- Toxicology predictor programs - he has never felt that there is anything out there that is that useful

- QSPar

- Top Cap

- Bruce Gelin - small consulting firm looking at all the types of programs

- Some people are trying to do everything

- Quantum mechanical calculations - people are satisfied

- Spartan

- Gausian

- Schrodinger - thinks they can find a niche in material science

- Have $100 \%$ of the market

- Product based diversity - 1500 algorithms that the chemist could do in his library...he doesn't know what is good and what is bad

- Fundamental challenge around combinatorial explosion

- Computational limitations

- Combination hardware/software problem

- Are there other ways of expressing diversity?

- Starting to introduce 3-D descriptions

- How do you validate that they are scientifically relevant

- Nobody is really doing much with shape right now

- Andy Gran at Zeneca doing shape descriptions

- Optimal design methods - optimal design picks outliers and tests nothing else that is similar

- Examples of problems in computational chemistry

- Introducing shape is solvable - have host of ideas of how to take these problems and have to pick one

- May turn out that one is well suited to these types of designs

- Toxicology - computational work less a part of their process in development...it's a lot more unusual 
- He would like to know what its crystal forms are...need to be able to control crystal ligand of subject...currently only capable of handling less rigid molecules 


\section{Mark Murcko \\ Senior Scientist, Computational Chemistry \& Molecular Modeling \\ Jay Knowles, Director, R\&D Planning 7/17/96}

- Three main areas of Molecular Modeling

- Visualization Systems

- Allows one to see molecule or data (animation, color)

- Main products: "Insight" and "Quanta" both sold by Molecular Simulations and "Sybyl" sold by Tripos

- Hard Core Number Crunching

- Evaluating energy of protein

- Background of programmers is in physics, applied mathematics

- Does not require knowledge of biology

- Written in Fortran

- Similarity

- Gauge similarity of two molecules or biological/biochemical systems

- Write codes assessing similarity

- Written in C

- Background of programmers is in computer science

- Written by geeky programmer types

- Conceptually broadly understood

- Number crunching overlap at times

- Codes that work most effectively are written by guys not like the Russians

- Russians primarily involved in the hard core number crunching, but are very bright and could help out with the visualization systems and similarity

- All three categories used by drug companies

- Various areas of hard core number crunching category

-Molecular Dynamics...main product is "CHARM" sold by Molecular Simulations (they sell software in all three areas)

- Quantum Mechanical: "Gaussian '94" has 1/2 of Quantum Mechanical Market

- Force Fields

- Free Energy Perturbation--- "Amber" is the big product ... "Amber" and

"CHARM" compete against one another...calculates how efficiently a drug will bind to its protein target ( 1 per month simulation)

- Russians specialization: applied mathematics, speed, algorithm development, efficient hard core number programming, parallel code, port mode (moving code from one hardware platform to another)

- Big computer programs are the mainstay of every large pharmaceutical company, depending on the program it is sold by seat or by site (e.g., Amber and Gaussian are sold by site)...every large company uses Charm, Gaussian and Explore and each of these products generates anywhere from $\$ 1-10$ million per year - upgrades are potential revenue sources

- Don't yet have results from the Russians...all indications are that it's "for real" 
- $\quad$ Russians need direction --- you have to explicitly explain the problem; they can also optimize the existing software, but not all programs are optimizable

- For a well-defined problem, they might say "here's how you could do it" or "here's how you could make improvements" or offer insights into new ways of performing the same calculation

- $\quad$ Steve Younger is a high energy physicist who could help define vague computational chemistry problems but it's not his strongest suit

- Pharmaceutical use is only one aspect of this field...there's also the polymer/material sciences side

- $\quad$ Solving these problems could require the same skill set within different functions and there are different types of integration techniques---not every problem is distinct (code cross/applicability)

- Companies use the software to solve a 3-D structure or to make a prediction (e.g., understand why some compounds work and some don't)

- As long as Russians are given directions, programming skills are robust

- Central issues is how well focused are they? There are also management issues and travel expenses to think about

- Not a lot of companies in Boston with big computational chemistry groups.... Vertex is the biggest at 20 people

- Interface issues with these programs not critical because small group of highly technical scientists using them

- Current software is usable as is -- no add-on code is generally necessary

- Goals: free energy simulation in a day, 3 month shortening of crystallography process, determining method of modeling protein/DNA 3-D folding 


\section{Contact Names}

East Coast/South/Midwest

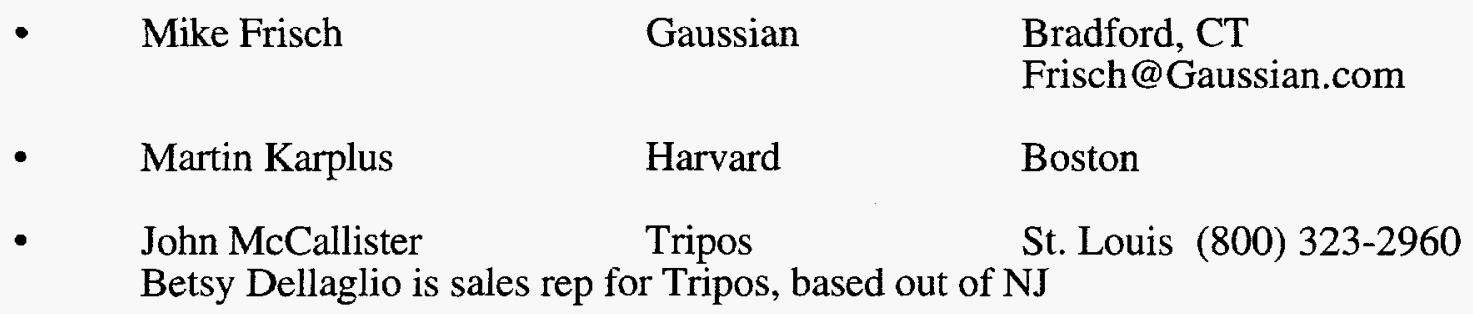

- Alex Brunger Yale New Haven

wrote Explor to solve protein in crystal

structures; first version generated in Martin Karplus's lab at Harvard
- $\quad$ Cary Stoych
BMS-
Princeton, NJ

Does molecular dynamics simulation

- $\quad$ Frank Brown

Glaxo

Research Park, NC

- Dennis Underwood

Merck

West Point, PA

he's high up in the modeling group

- George Lauri

Pharmacopiea

Princeton, NJ

\section{$\underline{\text { West Coast }}$}

\begin{tabular}{|c|c|c|c|}
\hline • & Peter Coleman & Prof. at UCSF-- & $\begin{array}{l}\text { San Francisco --wrote Amber } \\
\text { and knows everybody in the } \\
\text { industry }\end{array}$ \\
\hline - & Jim Wells & Genentech & San Francisco \\
\hline - & $\begin{array}{l}\text { John Wendloski } \\
\text { he's in charge of modeling an }\end{array}$ & $\begin{array}{l}\text { Amgen } \\
\text { dd crystallography }\end{array}$ & Thousand Oaks \\
\hline • & Jeff Blaney & Chiron & South San Francisco \\
\hline . & $\begin{array}{l}\text { Steve Freer } \\
\text { he's the interface between cry } \\
\text { and modeling }\end{array}$ & $\begin{array}{l}\text { Agouron } \\
\text { stallography }\end{array}$ & San Diego \\
\hline
\end{tabular}

Other Companies: Biogen, GI, Ariad, Procept

Titles to contact: Heads of Modeling; Biophysics; Directors of Molecular Modeling, Computational Chemistry; Structural Biology, Medicinal Chemistry 


\section{Dr. Barry Robson \\ Gryphon Sciences \\ August 27, 1996}

- Similarity is the key area in which the Russians could interact

- Underlying math problems

- "Multiple-minimum" problem

- Confirmational space is always different

- One seeks to find deepest energy minimum: need more high powered searching tools

- Want to find condition of least energy...this is a mathematical problem

- Underlies the protein prediction problem

- Higher problem is the "multiple attractor" problem - corresponding dimensions are the problem -- knows the Russians are great at doing this

- General solution: implications are far greater than just in modeling

- Dirac theorem- can calculate everything but would take loads of time

- Information theory is the underlying problem....making use of external information from outside

- Extra information

- Information specific to system - ex: binding data

- Information on general class of molecule - ex: database for whole class of molecules

- Infor inherent in human

- Expertise -- "judicious expertise"... "efficient interaction" --. "expert systems"

- Virtual reality - expert will do it and then leave and nobody else can do it....the same expert is going back the next day and not get the same result

- Need to capture the expertise in some system...... "reproducibility" is cornerstone of science...interactive visualization is 'garbage' because of multiple-minimum problem

- Problem - getting the expert to say exactly what he did is very difficult

- Modeling expert is not sure why he does things

- Knowledge engineer: broker between expert and system

- Teach language to expert and he can write it down in that language...need to bypass visualization

- Keeping a record of graphics internally is a waste

- Need to construct a high level language for molecular modeling...provide a language between Russia and U.S. -- capture expertise

- Provide language vehicle that explains what the Russians are doing

- Integrate extensive information with simulation could be co-developed

- Simulation will still be important - mindless screening won't solve everything

- No public computer databases with rate constant

- Toxic Effects

- Must look for patterns in toxicity

- If you know everything about the gene it would be the same problem as design -could find alternative target

- Toxicity: a few things going wrong, not a thousand things going wrong

- Goal is to take things from the expert system and make it usable by the non-expert

- Different levels of instruction

- Usually the design team has a free hand in deciding

- SBK - intelligent genomics the way to go --made by top management

- Pull all the systems together in an integrated way: Oxford Molecular is bad at this; Tripos is pretty good

- Jin Li- integrated drug design system ...Proteus has implemented 01141625500555

- Real integrated molecular systems 
- Java applets - security problem

- Networking - best but worst for security---he doesn't see any way for avoiding it 


\section{Paul Scharifson \\ Glaxo \\ August 22, 1996}

- Two prong approach

- Structural information

- Don't have structural information

- Large libraries of compounds - combinatorial chemistry design: will continue to be useful tool

- Overlaying problems that supersede technology: inability to get at issues such as toxicology/metabolism/could accurately calculate PKA of molecules - certain experience not a lot of organized

- Every company: MSI; BioSyn; Tripos; Oxford Molecular

- Macromodel - Columbia University (well thought out)

- 2 camps

- Commercial

- Academics programs - write a lot of their own programs..visualization (non issue) don't have to be wedded to do certain things

- Good thing about academic programs is that they have access to authors themselves can fire email message

- Have source code to the program - big companies don't give source code

- Expert users don't want to look at in a "black box"

- Have experts for non-users...do not use commercial all the time

- MSI - Explor...crystallographic refinement..general purpose energy tool high quality force field

- MCSF - have protein...could take small pieces of molecules and saturate protein segments with fragments...new molecules called novo design...helping decide catalysts...combinatorial chemistry set of tools for designing large sets of explores

- Suggested ideas; MCSF - have protein...could take small pieces of molecules and saturate protein segments with fragments...new molecules called novo design...helping decide catalysts...combinatorial chemistry set of tools for designing large sets of explores

- Suggested ideas

- Ability to calculate energy in a rapid environment

- Have so much overlapping functionality

- Vendors not creative in selling some parts of functionality

- A lot of companies buy internationally which gives them more bargaining power

- Merger between Glaxo/Burroughs Wellcome made it difficult for vendors

- Can't spend money on maintenance/decisions

- Decisions made on scientific basis: 2 months purchasing time

- Vendors watching academic institutions/citing academic expert as being validation

- Tripos - package of small choice for small molecules

- Unity - have good database searching (marketing themselves for database products)

- Disco - useful for pharmakor model

- Bioinformatics - people getting sequencing...molecular biology...is the driving force for getting large scale networking in house...tools are biology-oriented

- Chemo-informatics - QSAR/quantum structure actual realization...what computational chemists have been doing for years

- People who do chemo...2D not 3D representation

- Commercial companies love consortiums...every consortium has produced minimal in everything...advantages have not outweighed the pain factor

- Drug Research 
- Solvation models: continuous solvations models - try and generate the field effects of water around molecules

- Have reached limits on physics ...hard core problems that react molecule of $\mathrm{H} 2 \mathrm{O}$

- Flexible molecule targeting..shape of protein changes it binds to a drug molecule

- Scoring function: how do you determine which idea is better - calculate ability of structure-based energy between A\&B---but this is not easy to do

- People come up with crude mathematical models as to how to get this answer

- Need for better molecular mechanics programs/quantum chemistry...Merck has own force

- Most research being done academically

- Similarity: combinatorial chemistry design - nobody knows how to do it right

- $100 \mathrm{~A} \times 100 \mathrm{~B} \times 100 \mathrm{C}$ - ? given that you could buy 100 , give him the 10 that are most dissimilar..simulation becomes dissimulation

- Whole area for calculating 3D models

- If you could solve the problem, you would contract out the research/you wouldn't sell the software

- Chemical Design - "hard to use" but creative

- These programs have room for significant improvements, but will improvements really improve the bottom line

- Ultimately it will get to larger issues of metabolism

- To really solve the problems, need a lot of high quality experimental data...usually not designed for purpose of designing algorithms

- Large percentage of error on a lot of experimental data

- QSAR - people take 30 or 40 molecules and use multiple linear regression

- Toxicological world

- Some good data --- need to evaluate which data is good and which data is bad

- Can't consistently design molecules to bind to protein site

- 2 levels - more pragmatic...higher level of toxicology

- Development: being able to test absorption of a drug...come up with a scheme to test

- PKA - physical properties not optimal for producing on a large scale

- Acquires solubility

- A lot people thinking about these problem developed algorithms

- How water soluble a compounds

- Product development realm - has not been addressed with full focus by commercial companies

- Commercial companies try to be all things to all people

- Biopharmaceuticals - pharmacy schools -- these people end up in development...not computer literate (in general)

- Whole host of formulations issues

- Development issues a "black hole"

- Platform dependent - $\$ 100 \mathrm{~K}+$ but generally in $\$ 50-100 ; \$ 10-50 \mathrm{~K}$ year maintenance

- Chemical Design - creative but hard to use 


\section{Gennady Verkhivker \\ Agouron Pharmaceuticals \\ August 1, 1996}

- He's from Russia

- Talked about a company in the Ukraine that contacted him...looking for funding...in the material sciences area..had an explicitly outlined titled of projects...chemists so their research is more related to healthcare

- He's a theoretical physicist/mathematician

- We used to have low computational chemistry systems, but would be at the high end for Russia

- They don't have the facilities that we have

- Russians do have skills in chemistry

- Most facilities and equipment built by them

- Scientists in Arzamas-16 wouldn't have any idea of the technology/graphics/software used in the U.S.

- Could not do visualization, but perhaps simulation; molecular similarity

- They would need training

- For visualization, the level and quality of the software is so high that they wouldn't be able to get up to speed

- Simulation -- an option for Russian skills

- Optimization models: still room for improvement here. Optimize arrangement of ligand and protein and optimize degrees of freedom

- Must determine better way to determine how drug binds: molecular docking systems

- Physicists and mathematicians would be good at this

- Optimization -- function of many variables; have to optimize core problem

- Could make a reasonable impact on optimization, but the fact is that they are working in Russia and don't know what's going on...but could make reasonable impact

- Simulation models - important to all pharmaceutical/biotech companies

- A lot of big European companies do simpler modeling of their database drugs. They have a different approach to drug discovery than start-up biotechs as a result of the large libraries of drugs they have on hand and their knowledge, based on what they have developed, on which molecular permutations work. Research is much more traditional. New techniques such as computational chemistry does not have as big of impact as in the U.S.

- Drug design related artificial intelligence is a key element...programming not hard...need to come up with interesting artificial intelligence

- Neural network: have a number of compounds with given activities and properties; each is charted by their properties; now build a neural network, look at new compounds and assess activity.

- Another party would have to identify the problem for the Russians; they would only be able to implement.

- Russians should work directly with pharmaceutical companies because the software companies are only interested in selling software...they would take algorithm and implement it and sell the package...pharmaceutical companies are interested in designing drugs...have problems that can be addressed so the Russians could actually work on problems instead of just developing code

- If they can come up with a new methodology, the company would like to keep it proprietary...Agouron has consultants saying that they can't use techniques for other drug design companies

- How can they market themselves? 
- Publications in the health care field

- Resumes

- Give their book, applications, resume, record to an expert and ask if their proposals are reasonable

- Scientific Applications International Corporation -- offices in Moscow...they use the Russian scientists for physics, math, optimization...Pam Surko at SAIC worked at Agouron as a consultant

- Thinks Russians could be helpful if utilized properly

- Don't need a big investment 


\section{Marvin Waldman \\ Molecular Simulation \\ July 31, 1996}

- Modeling broken down by application for structure-based design versus application for classical or analog-based design

- Analog-based design: don't know the receptor target; involves molecular similarity; look for patterns that make a compound active/inactive

- Simulation: used to design a molecule knowing what the "lock" is

- Similarity: used to design a molecule not knowing what the lock is, but knowing which kind of keys will fit in the lock

- Visualization: graphic/predictive modeling

- Thinks that language/communication will be a big issue with the Russians

- Developing software involves having it work in language of a chemist; it is not straight software programming

- A lot of these problems involve physics/math: graph theory

- They are flexible about computer language: Fortran is acceptable but not desirable; Java or $\mathrm{C} / \mathrm{C}++$ is preferred

- They usually license the software from academics in $\mathrm{C}++$

- He is very skeptical when we say that they are faster/more efficient...the extra talent gets washed away by overhead communication/costs. Foresees integrating them in the company is difficult

- The benefit would have to be 3-5 times the speed of development to overcome communication distance; would have to make sure that the problems are well defined.

- Need a strong math and chemistry background to understand the right way to describe chemicals in a way that's suitable for database

- In his mind there would need to be some training in chemistry

- Material science modeling is another option --MSI has a lot of software in this area

- MSI history: MSI formed from Biodesign and Cambridge Molecular. MSI was then merged with Polygen to form Polygen/MSI, later renamed MSI. MSI then purchased Biocad and most recently purchased Biosym, which was owned by Corning. As a result of the Corning investment in Biosym, Corning owns a majority (51\%?) of MSI.

\section{MSI Products:}

\section{Life Sciences Products}

a. MacroMolecular: Structure Refinement, and prediction of proteins, DNA and nucleic acids

- NMR (will give structure in solution): NMR architect

- X-ray (will give crystal structure)

- Homology modeling

- Reverse folding

b. Drug Design

- Analog Based

- Molecular similarity (comparison)

- Determine 3D patterns that correlate with biological activity

- Products: Catalyst; Receptor, Confirm: Search/Compare, QSAR

- Structure-Based

- You have the receptor structure and you try to fit or dock small molecules (Ludi, MCSS/Hook, Affinity) 
2. Material Science Products

- Products for zeolites, surfaces, sorbates, morphology

- Large pharmaceutical company would buy all of the above products for "hundreds of thousands of dollars"

- A lot of time is spent integrating, documenting, debugging... only $20 \%$ of time is spent developing novel algorithms

- Have capabilities for users to tinker with the software and customize software for their own needs because science not yet mature...need tinkerers..still a lot of unknowns/ not totally predictive

- Nobody will buy it until you prove that it actually works. All software must go through rigorous validation process

- Oxford Molecular is acquiring a lot of companies...have a lot of "cash on hand." They are way overvalued.

- Market is saturated, accounting for the significant consolidation that has occurred over the years

- Overall market opportunity for any one software product is \$5-10 million dollar range

- Opportunity lies in expanding the market to non-experts: medicinal chemists/non computational chemists

- MSI \& Tripos are the two major players; next is Chemical Design and Oxford Molecular

- Total market: $\$ 100-\$ 120$ million

Major Players:

- MSI - \$50 million

- Tripos $\$ 25-30$ million

- Oxford Molecular - \$10-15 million

- Chemical Design - \$5-10 million

- MSI is the only company in material science

- Their drug design products are in over 1000 sites

- Usually takes 1-2 years to develop a product. They will often organize a consortia of companies to underwrite a product's development and help in validation of a product

- Oxford Molecular licenses academic software and resells it...usually not robust products.... a lot of lower end users

- He's had bad experiences working with developers in remote countries

- Programs are not user-friendly

- Programs are often not well validated....this makes it difficult to market the software

- He's seen a lot of clever things, but issue of designing a drug is in reality a lot more complicated...these problems have been worked on by very smart people for 20 years...he remains skeptical that anyone could be that much better than the code writers he currently deals with

Additional Contacts

- Abbott - Jonathan Greer/Charlie Hudson

- BMS - Terry Stout

- Dupont Merck - Nick Hodge

- Zeneca - Brian Massic

- Merck - Simon Kearsley

- J\&J - Hershel Weintraub

- Upjohn - Gerry Maggioria

- Pfizer - Jim Matthews

- Rhone Poulenc - Jon Mason

- The above are computational chemists...they make the purchasing decisions...they have both published and developed software 
- Key journals in the industry: Journal of Computational Chemistry; Computer Aided Molecular Design; Physics; Graphics 


\section{Dave Weininger \\ Daylight Chemical Information \\ August 1, 1996}

- Russians are very good at writing extremely efficient code

- Healthcare/pharmaceutical modeling a shrinking field

- Electrostatics is a tough problem

- Would like to be able to predict a three dimensional structure from a one dimensional representation

- Need to ask what problems could be solved mathematically

- Issue is managing abstractions and understanding chemistry versus just programming

- Having code is great, but if it's not relevant to the problem, it's not useful...that's why biotech is tough because the problems are always changing

- Chemical space is ill-defined/abstract

- Chemists can't predict how molecules get together

- Waiting for some great breakthrough to show how proteins unfold

- Sophisticated algorithms needed to explore conformational space of how proteins bind together

- An appropriate problem would be some algorithmic problem that they could solve mathematically. Example: electrostatics

- Two approaches to modeling protein in $\mathrm{H} 20$ : treat $\mathrm{H} 20$ as a continuum - average presence; or treat it atomically

- Ewaad Summation - replicate molecule so you can solve problem more efficiently

- Thomas Darden - mathematician - Bethesda

- Michael Holst...multigridding..way of solving partial differential equations...complexity is optimal

- Could talk to companies who do simulations and have their own code. Also, there are companies that you could sell simulation code to. Realistically this could form the basis for a new company - anyone doing large scale simulation

- Chemistry is a very insular field..they are not interested in math and vice versa

- Implementation is not that big of an issue...theory is the big issues and they really need to understand what the core problems are

- Some problem is waiting to be solved but the theory is not known

- Generalist would be good, but these people haven't been involved in biotech

- Can't really contribute until you totally immerse yourself in the field -- mindset is very different

- If they participate in understanding the business it might work, but if they think they're just going to sit and write code and not participate it won't work

- Rental car and airplane scheduling could use their help!!

- One drawback is that they're not in our programming language but if they're really great switching languages doesn't matter

- No recent college grads in Fortran so it is difficult to support Fortran code. Most of what makes software companies tick is support...need to be able to support product in $\mathrm{C}++$

- No commonality between now and 20 years ago about how software is made and sold

- May be extremely good at something that we're not that bad at

- Real difficult thing is being connected to what's going on -- implementation is the key

- Can't just write down the problem and have them solve it. You are asking for problems where the theory is known but people haven't been able to sit down and write the code.

- We have a come a long way the past 20 years but it has not been due to improvements in the speed and efficiency of code.

- Solving differential equations would be having a new method for programming

- They should come over here and have a conference and validate what they can do 
- Dimacs -Rutgers - Ron Levy

- Tim Havill - Harvard

- Gordon Griffin - mathematician at Michigan

- Scroninger, Rich Freisner at Columbia

- SGI Magnet - Israeli technologies..have big thing for technologies/pharmaceuticals

- Get their CVs; techniques used; methodology 


\section{Hershel Weintraub \\ J\&J \\ August 22, 1996}

- $\mathrm{J} \& \mathrm{~J}$ doing more work in small molecule area, less in large molecules

- Small molecule focus -- needs rapid making and testing of virtual libraries...docking compounds into target algorithms

- Large molecules used to prep virtual libraries...Everything has to be rapid

- Virtual library creation - docking algorithms molecules to library to get structures ready do to screening

- $\mathbf{J} \& \mathbf{J}$ gearing up for combinatorial chemistry...software using for honing down the number of possible hits

- 3D QSAR program - statistics, quantitative

- Need long term protein modeling

- Database searching - Unity - flexible algorithms searching

- Diversity estimation -- buy or trade compounds

- Electronic screening on real corporate database

- Will have to do predictions of compounds

- Traditional 3D databases

- J\&J has mostly commercial programs - they have every module Tripos/MSI products; except for diversity estimation software

- They also have various smaller programs such as Molecular Applications Group

- 50 software packages such as Tripos/MSI

- Weintraub makes final purchasing decisions

- Approach is to have large toolbox, just writes interfaces...used qualitatively due to inaccuracy of programs

- Big problem - keeping older programs running, debugged

- Software interface won't let you do what it obviously can

- System crashes when certain combinations of modules used

- Single visualization and modeling should be for "novice" users...program pitfalls would fall through novice's sieve

- Gradual improvements seen in docking algorithms - relative binding affinity

- Combi chemistry will eventually peak and tail off...then build virtual library from honing from combinatorial chemistry

- Key is speed - UCSF/Kuntz...needs a couple of days on mid-level multiprocessors...DOC- rigid ligand/target

- New Scrip program takes a couple of hours...very flexible

- CRAY platform - lack of software...when bought, molecular dynamics big, less important now

- SGI - virtually every program runs on these machines

- "Academic" applications not generally picked over commercial due to product support issues

- Despite successes, (top 40 compounds came from modeling), management doesn't recognize value of modeling

- Lots of money is spent on high throughput screening -- hard to backtrack

- Modeling difficult synthesis -- have had a few "successes"

- Prediction software of toxic effects still inadequate...very little done early in development

- Experimental

- "Traditional" - Oracle/MSI....use to gather information/do things qualitatively

- Commercial companies devoting time to keeping pieces already sold running rather than devoting time to new products

- Software interface won't let you do something you want to do they will crash 
- Purchasing depends on company and management strategy - ease of use

- Ability to interact with expert groups

- Visualization - belongs on desktop

- Methods where ease of use makes it difficult

- Complicated simulations - done with expert group or in tandem

- Docking algorithms - assess relative binding affinity

- Combinatorial chemistry will peak and tail off - another method for rapid evaluation

- Can't make a million compounds

- Ability to filter infinite library down to a few thousand molecules

- Explore possibilities around the hits...even if you make them, you still have to store them

- Scripps - scoring system for docking algorithms

- Fast, accurate binding affinity

- Speed is the most important

- DOC - UCSF

- Go through corporate database - takes a couple of days 10,000

- Scripps - 1 molecule at a time/few hours per molecule

- DOC is a molecule rigid receptor

- Need to get more software that runs on the Cray platform

- Virtually everything runs on Silicon Graphics

- Price secondary except vendors come in with aggressive pricing for new product

- Won't pick academic versus commercial if they do the same thing because of product support issues

- Price is not really an issue

- Academic software - will support a postdoc to get sufficient support

- DOC-UCSF

- Sybl - Tripos - most valuable (includes Unity)

- U of Texas - looks part of graphical/diversity estimation

- Molecular Applications Group - Look easiest to use/not a lot of results

- Spartan - to compute electronic molecules

- Top 40 hits in the program come out of modeling...beyond that it is the traditional physics and chemistry

- They spent millions of dollars to do high throughput screening

- Had major success in four projects

- Not getting funds before because they are going to robotics

- Tough to change the mindset of management - no real respect from top management

- Modeling to drug development - helping in difficult synthesis

- Suggests that kinetics were driving the reaction

- Preparing for clinical trials

- $\quad$ Prediction of toxic effects

- Very little toxicity tests early in the development process

- Predictive programs are look-up table type that produce results that toxicologists same as what went into model

- Several year period

- Scientific problem ??

- Toxicology experimental results kind of flaky

- General algorithm and knowledge-based software...doesn't like to see the line between the R \& D...have toxicity...move tail end of discovery

- Experimentalists - don't believe in computers

- As younger people move into top management, it could change things, but some are there in the first place because they don't like computers

- Steve Gallian - ArQule...head of computer group..how small biotech company handles data and follows guidance

- Incyte - developed database software...genomics...comp. of Molecular Informatics 